\title{
Research on Coupling Degree Model of Safety Risk System for Tunnel Construction in Subway Shield Zone
}

\author{
Haize Pan, Jing Gou, Zihong Wan (D), Chuxuan Ren, Mengjie Chen, Tangqiao Gou, \\ and Zhenhua Luo \\ School of Civil Engineering and Architecture, Southwest Petroleum University, Chengdu 610500, Sichuan, China \\ Correspondence should be addressed to Zihong Wan; swpuwzh12222@hotmail.com
}

Received 26 June 2019; Revised 24 September 2019; Accepted 16 October 2019; Published 18 December 2019

Academic Editor: Stylianos Georgantzinos

Copyright (C) 2019 Haize Pan et al. This is an open access article distributed under the Creative Commons Attribution License, which permits unrestricted use, distribution, and reproduction in any medium, provided the original work is properly cited.

\begin{abstract}
Due to the complexity of construction technology and the seriousness of the safety situation in subway tunnels, it is urgent to find a risk-control method to monitor and evaluate the construction safety risk system of the subway shield tunnel and to avoid the occurrence of safety risk accidents. Based on the fuzzy entropy theory, this paper establishes a comprehensive index system for the construction safety risk system of shield tunnels. Also, in order to quantitatively analyze the coupling degree among various factors in the safety risk system, the calculation model of coupling degree is established based on the theory of coupling degree in physics. Taking Tianjin subway project as an example, the coupling degree of its safety risk system is calculated. The result shows that the coupling degree of the safety risk system is 0.6997 , which indicates that the whole safety risk system is in high-risk coupling level. Due to the system in an unbalanced development stage, the coupling movement between various factors has a great destructive effect on the construction safety risk system of the subway shield tunnel. This model can not only identify the main risk factors affecting the safety risk system but also monitor the coupling status of the safety risk system in real time and master its development stage. By controlling the main risk factors affecting the safety risk system, the coupling degree of the safety risk system and the probability of the safety risk accident occurrence can be reduced.
\end{abstract}

\section{Introduction}

Nowadays, with the rapid development of economy, the speed and accessibility of traditional vehicles, such as automobiles and trains, can no longer meet the travel needs of modern people. Urban rail transit has become the most popular traveling mode [1]. By the end of 2017, there were 34 urban rail transit operation cities in mainland China, 165 rail transit lines, and $3168.7 \mathrm{~km}$ of subway lines, accounting for $77.2 \%$ of the total length of rail transit operation line [2]. During subway construction, potential safety hazards exist due to complicated construction process and uncertain factors. According to statistics, there were 246 subway construction accidents between 2002 and 2016, of which, 43\% collapse accidents, 19\% high-altitude falling accidents, and $14 \%$ object impact accidents [3]. Therefore, the key to ensure the construction safety is to do the subway construction risk assessment well and to effectively control and manage the risks as well.
In recent years, researchers have conducted a comprehensive study on safety risk management of subway construction and paid sufficient attention to the risk assessment, control, and management of subway construction. Yang applied a comprehensive evaluation model based on the fuzzy matter-element method to analyze and evaluate risks [4]. Zheng and Lee proposed to evaluate, control, and manage the construction risks of the subway tunnel adjacent to the tunnel by combining ANP-FE with numerical simulation [5]. Reilly presented an overview of management for complex, underground, and tunneling projects [6]. Wu et al. realized comprehensive analysis and evaluation of subway construction risks by using the relevant theory of Bayesian network [7]. Based on reliability theory, Isaksson analyzed the construction risk of tunnels and underground engineering [8]. Sousa and Einstein presented a geologic prediction construction strategy decision model to assess and manage the risks associated with 
tunnel construction systematically [9]. Samantra et al. proposed an integrated risk assessment route in relation to metropolitan construction projects based on the fuzzy set theory [10]. Among them, many researchers reveal the destructiveness of various risk factors to the safety system by studying the uncertainty of construction risks, such as Liu pointed out that when the construction machinery breaks down and fails to be repaired in time, the function of construction machinery will deteriorate, the value of construction machinery will be reduced, and even engineering accidents will be caused [11]. Xiao pointed out that the cause of large-scale geological settlement at the construction site of section C824 of Singapore Metro Loop Line was neglecting local geological environment by the constructor [12]. Shang pointed out that the large-scale construction accident of Shanghai Traffic Line 4 was caused by illegal operation and negligent management [13]. Yang pointed out that the shortened construction period in Shenzhen Metro construction project was caused by lacking of construction management, which led to a great loss of the project [14]. Zhang pointed out that the collapse accident of Hangzhou Metro Station was caused by illegal operation of construction units and local geological environment [15]. The above research shows that in the construction, machinery, personnel, environment, management, and other aspects are the causes of accidents. However, these risk factors are uncertain and difficult to control, and they affect and restrict each other, which greatly increases the difficulty of construction risk control. Therefore, it is particularly important to research the form and movement of the interaction between risk factors.

So far, in-depth study has not been conducted on coupling motion among risk factors in the system. Ren proposed a risk coupling model, which could be used to analyze the spatio-temporal evolution of the coupling risk of deep foundation pit construction in subway station [16]. Ma studied the risk coupling of urban rail transit operational risks [17]. Wu et al. studied the coupling of subway construction safety risks by using the $\mathrm{N}-\mathrm{K}$ model in order to calculate the probability and risk value of different risk coupling situations [18]. Wang used the N-K model to calculate the risk coupling value and probability value of human and environmental safety factors in subway safety accidents [19]. These studies did not specifically research the safety risk system of shield tunnel construction nor the coupling state of the safety risk system.

In summary, there are few research studies on the complete establishment of the comprehensive index system for construction safety risk system of the shield tunnel and the coupling state of the safety risk system. The purpose of this paper is to analyze the characteristics of subway tunnel construction and the causes of the accidents and to establish a comprehensive index system of the construction safety risk system based on fuzzy entropy theory. By introducing the coupling degree model into the construction safety risk system of the subway shield tunnel, the coupling degree of the system is calculated to achieve the coupling state of the monitoring system and its development stage.

\section{Coupling Mechanism}

The term of "coupling" is originated from physics and is a phenomenon in which two or more systems or forms of motion interact with each other [20]. The risk coupling of the subway shield tunnel refers to the dependence degree of individual risk occurrence on the occurrence of other risks, and the degree of influence on other risks, the greater the dependence degree among risks, the greater the degree of coupling [21]. The calculation of system coupling degree can be realized by the $\mathrm{N}-\mathrm{K}$ model, the coupling degree model, the interpretative structural model, and the nonlinear dynamic model. Compared with other models, the coupling degree model has the advantages of low sample requirement and simple calculation and has been widely used in urban development and ecological environment [22].

The coupling degree model is used to describe the degree of mutual influence among system or elements. The key to system from the disorder to order mechanism depends on the synergy between the order parameters within the system, which determines the characteristics and laws of the system changes. The coupling degree is a measure of reaction synergy, that is, the intensity of the interaction of order parameters in each system [23]. In the construction of the subway tunnel, all risks affecting the safety system will not be coupled simultaneously, which exceeds the maximum threshold that the safety system can withstand and breaks through the defense system [24]. Among them, a part of the risks first breaks through the defense system and carries out coupling activities accordingly.

This paper uses the coupling degree model to calculate the coupling degree of the construction safety risk system of the subway shield tunnel. The specific research details are as follows. Firstly, determining comprehensive indicators of safety risks by analyzing on-site accident causes and related literatures. Secondly, based on the theory of system dynamics, the risk coupling analysis is performed for the subway shield tunnel to establish a multifactor risk coupling model. Thirdly, a computational model is created. The first step is to evaluate the risk level of the comprehensive safety risk index by using the expert survey method and to divide the risk level of the index. The second step is to use backward cloud generator filtered by risk evaluation results. The third step is to judge the consistency and objectivity of the initial screening indicators by using normal cloud generator and to repeat the second step to get the definitive expert evaluation data. The fourth step is to determine the weight of the safety risk comprehensive index by fuzzy entropy theory, establish the efficacy function, and get the most harmful factors in the safety risk system. The last stage is to establish a coupling degree function to find the coupling state of the safety risk system and its development stage. Finally, the calculation results are obtained through case analysis, and corresponding control measures are submitted for higher risk factors. The exact research framework is shown in Figure 1. 


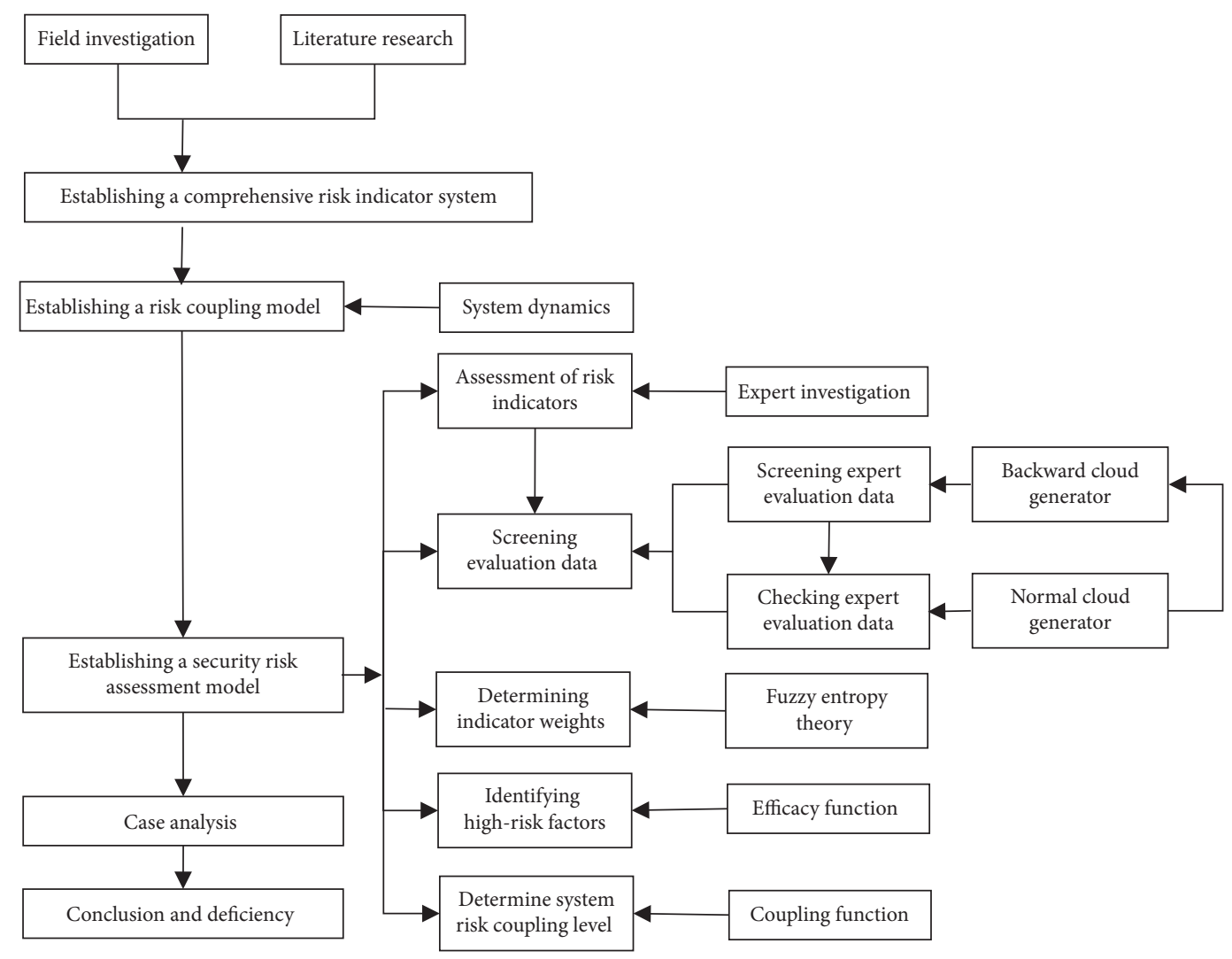

FIGURE 1: Research idea framework.

\section{Model Establishment}

\subsection{Establishment of Comprehensive Index System}

3.1.1. Statistical Analysis of Safety Accidents. The shield method is the most common construction method in subway tunnels, which can achieve completely enclosed operation with little impact on the environment and small construction area [25]. Due to the complexity and uncontrollability of subway tunnel construction, safety risk accidents are very common [26]. By reviewing literatures [27-30] and field investigation, this paper collected 101 construction safety accidents of the subway shield tunnel in Beijing, Shanghai, Tianjin, Guangzhou, Nanjing, Wuhan, and Zhengzhou from 2006 to 2018. The statistics are shown in Figure 2. The accident cause and the objects of disasters are the important components of the construction safety risk system of the subway tunnel. The analysis results are shown in Table 1.

It can be seen from Figure 2 and Table 1 that collapse accidents, water gushing and mud-bursting, are common safety accidents during the construction of subway shield tunnels, and the occurrence frequency is high. At the same time, the main risk factors causing safety risk accidents during subway shield tunnel construction can also be analyzed, which include human factors, mechanical equipment factors, environmental factors, and management factors. These risk factors interact and influence with each other to destroy the safety risk system. For example, during the construction of the subway tunnel, the gas in the tunnel may

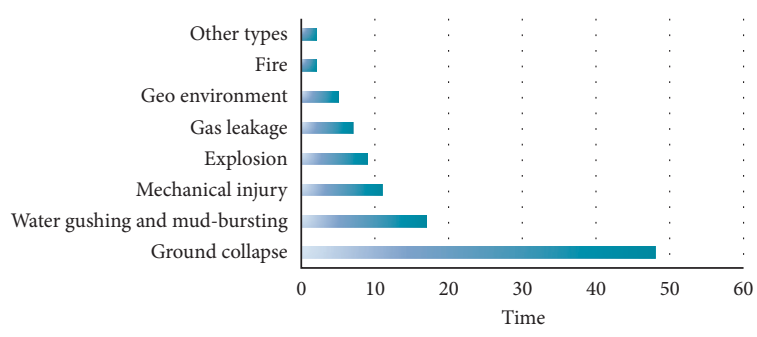

FIGURE 2: Statistical chart of safety risk accidents.

leak due to geological conditions, hydrologic conditions, and improper operation of the construction personnel, and so on, which may lead to explosion. Complex construction environments, such as tunnel section dimensions, will directly affect the flexibility and safety of the construction space and the constructors. Furthermore, it will also cause lack of machinery maintenance timely, coupled with the lack of safety awareness of construction workers, and so on, which easily lead to mechanical injuries and other accidents. Insufficient construction experience and lack of qualified technical personnel, as well as complex construction environment and natural environment, imperfect management mechanism, and irrational organizational structure, can easily cause collapse accidents. Therefore, it can be seen that during the construction of the subway tunnel shield section, various risk factors will interact with each other and affect the construction safety system together. 
TABLE 1: Statistical table of the causes of safety risk accidents.

\begin{tabular}{|c|c|c|c|}
\hline The accident causes & Frequency & Influence factors & Specific reasons \\
\hline Mechanical injury & 11 & $\begin{array}{l}\text { Human factors } \\
\text { Machinery factors } \\
\text { Environmental factors } \\
\text { Management factors }\end{array}$ & $\begin{array}{l}\text { Without certification } \\
\text { The lack of awareness of security } \\
\text { Machines in disrepair } \\
\text { Improper installation } \\
\text { Harsh working environment } \\
\text { Managers neglect their duties } \\
\text { Imperfect site management }\end{array}$ \\
\hline Ground collapse & 48 & $\begin{array}{c}\text { Human factors } \\
\text { Machinery factors } \\
\text { Environmental factors } \\
\text { Management factors }\end{array}$ & $\begin{array}{c}\text { Inexperience } \\
\text { Inadvertent operation } \\
\text { Low technical capacity } \\
\text { Machinery fault } \\
\text { Improper installation } \\
\text { The complex geological and working environment } \\
\text { Managers neglect their duties } \\
\text { Imperfect management mechanism } \\
\text { Unsound safe management system }\end{array}$ \\
\hline Water gushing and mud-bursting & 17 & $\begin{array}{c}\text { Human factors } \\
\text { Machinery factors } \\
\text { Environmental factors } \\
\text { Management factors }\end{array}$ & $\begin{array}{c}\text { Violation operations } \\
\text { Inadvertent operation } \\
\text { Machinery fault } \\
\text { The complex geological environment } \\
\text { The lack of awareness of security management } \\
\text { Irrational organizing structure }\end{array}$ \\
\hline Gas leakage and explosion & 18 & $\begin{array}{l}\text { Human factors } \\
\text { Machinery factors } \\
\text { Environmental factors } \\
\text { Management factors }\end{array}$ & $\begin{array}{l}\text { Inadvertent operation } \\
\text { Lack of ability to identify hazards } \\
\text { Equipment aging } \\
\text { Machines in disrepair } \\
\text { Unpredictable environment factors } \\
\text { The complex social environment } \\
\text { Imperfect site management }\end{array}$ \\
\hline
\end{tabular}

3.1.2. Establishment of Index System. This paper will determine the comprehensive index system of the safety risk system from two aspects: the causes of safety accidents in subway tunnel construction and the index system of relevant research results. In this study, 101 safety risk accidents of subway shield tunnel construction were analyzed. The induced factors of safety risk accidents were identified which include personnel, equipment, environmental, and management safety risk factors. The rationality of the index system is ensured by combining with the characteristics of subway shield tunnel construction and drawing lessons from relevant research results. For example, Cao pointed out that the main safety factors affecting subway tunnel construction include engineering geological and hydrogeological conditions, load factors, construction factors, and external factors [31]. Yang believes that human safety factors and mechanical safety factors are the main risk factors affecting the construction safety of subway tunnels [32]. Wu et al., Wang, and Liu et al. believe that the main risk factors affecting the construction safety of subway tunnels include human, machinery, environment, and management $[18,19,33]$. By supplementing and perfecting the index system of these literatures, a comprehensive index system for the construction safety risk system of the subway shield tunnel is formed, whose results are consistent with the analysis of the causes of the safety risk accidents.
The 4M1E (Man, Machine, Material, Method, Environment) method [34], also known as the factor analysis method, is a very important and universal construction site management element. By controlling the five factors, the purpose of well construction site management can be achieved. In this paper, the three 1st-level indicators are proposed according to the $4 \mathrm{M} 1 \mathrm{E}$ method: human risk factors, machinery risk factors, and environment risk factors. Also, another 1st-level indicator, management risk factor, is determined by the inducement factors of actual safety risk accidents and literature research results. It is worth emphasized that material risk factors are classified as management risk factors, in terms of establishing sound material management system, and so on, and method risk factors are classified as human risk factors, namely, low operational capacity of construction technology, and so on. The 2nd-level indicators are determined by the inducement factors of actual safety risk accidents and literature research results as well. The specific analysis is shown in Table 2.

The human risk factors are the 1st-level indicator, expressed by R1. In the construction of subway shields, personnel is characterized with uncontrollable and the direct cause of safety accidents. The human factors include three 2nd-level indicators: physiological factors (drunkenness, fatigue, and illness) expressed by R11, psychological factors (lack of responsibility, safety awareness, and concentration) expressed by R12, and technical factors (no certificates, 
TABLE 2: Risk assessment system for subway shield tunnel construction.

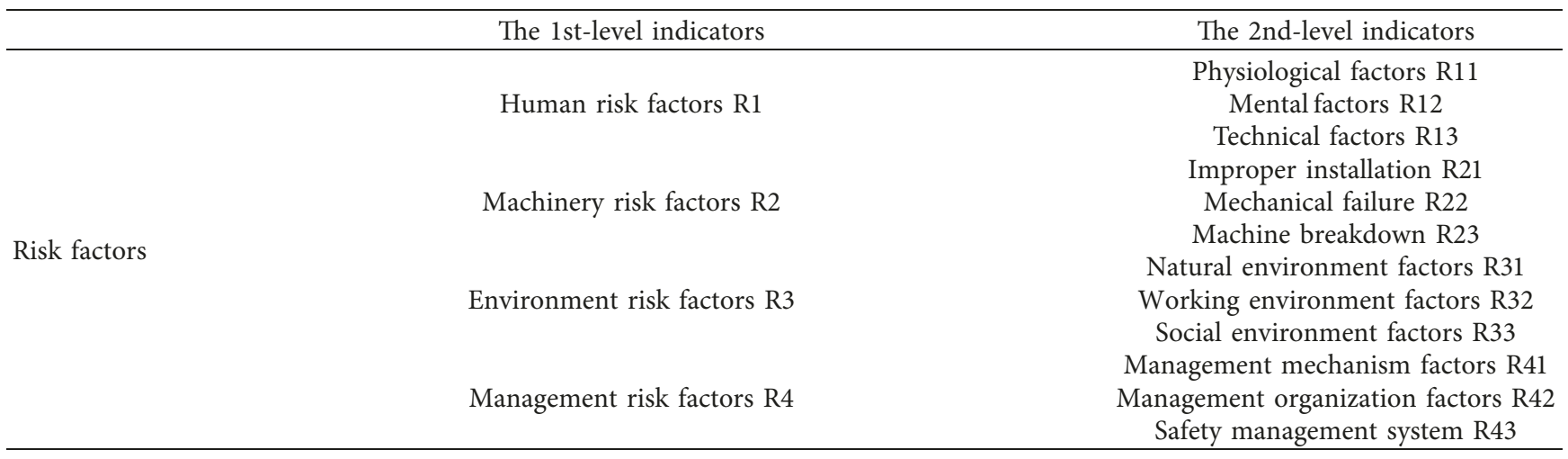

inexperience, low operational ability of construction technology, and inadvertent operation) expressed by R13.

The machinery risk factors are the 1st-level indicator, expressed by R2. Because shield machine is the main equipment during subway shield construction, the defects of shield machine and its auxiliary equipment are the important factors causing machinery and equipment risks, which include three 2nd-level indicators, the improper installation (expressed by R21), the mechanical failure (expressed by R22), and the machine breakdown(expressed by R23).

The environmental risk factors are the 1st-level indicator, expressed by R3. In the construction of subway tunnels, the risk accidents are often caused by the complex structure of the urban underground space, the hydrogeological environment, and the operating environment of construction personnel. Environmental factors include three 2nd-level indicators: natural environment factors (geological conditions and hydrological conditions) expressed by R31, operational environmental factors (operating space and operating conditions) expressed by R32, and social environmental factors (economy, labor, construction market, and national policies) expressed by R33.

The management risk factors are the 1st-level indicator, expressed by R4. These factors run through the whole construction process, which has close relationship with human factors, machinery factors, and environment factors and are the main influencing factors to evaluate construction risk control. The management factors include three 2 ndlevel indicators: management mechanism factors (emergency management system, daily management system, personnel performance evaluation system, and material management system) expressed by R41, management organization factors (management capacity of the project manager, management function conflict, and imperfect management organization) expressed by R42, and safety management system (safety training of employees and construction site safety management) expressed by R43 (Table 2).

3.2. Risk Coupling Model Analysis Based on System Dynamics. Common coupling models include SHEL model, system dynamics model (SD), interpretative structure model, and
$\mathrm{N}-\mathrm{K}$ model. The advantages and disadvantages of each coupling model are compared and the applicable fields are shown in Table 3.

The lack of complete historical data on subway tunnel construction risks, tunnel's own uniqueness and complexity, and various construction risk factors influencing each other make the risk system huge and complicated. Based on the construction risk management studied in this paper, it is necessary to study the relationship between the various risk factors which affect, promote, and restrict each other. Therefore, SD system dynamics model is selected to analyze the construction risks of the shield tunnel section.

3.2.1. SD Model. The modeling of system dynamics is carried out simultaneously both from the structure and function of the system. The structure of the system refers to the interaction between different subsystems in the system, which revealing the correlation and complexity of the system as a whole and obtaining relevant information through collecting and analyzing historical data, namely, quantitative information. The function of the system refers to the interaction between the internal units of the subsystem, which is judged by the builder's knowledge and understanding of the system's motion mechanism, namely, qualitative information. System dynamics combines the complete information of the system qualitatively and quantitatively to construct a reasonable and effective model that reflects the interaction of actual systems [35-37].

The cause-effect diagram is essential during generating the flowchart of system dynamics. The mutual restriction diagram among factors is formed by establishing the causaleffect chain (positive causal chain and negative causal chain) and causal circle. The positive coupling of risk is realized by triggering risk factor $\mathrm{A}$ to trigger and expand risk factor $\mathrm{B}$, namely, SD positive causal chain.

The advantages of the SD-based risk coupling model are as follows:

(1) System problems can be studied through limited data

(2) This model can be used to deal with complicated system problems with low precision requirements

(3) The model can be optimized through a large number of actual cases to make the model more accurate 
TABle 3: Comparison of advantages and disadvantages of each model.

\begin{tabular}{|c|c|c|c|}
\hline Model name & Advantage & Disadvantage & Application field \\
\hline The SHEL model & $\begin{array}{l}\text { Taking human as the leading factor, the } \\
\text { factors affecting safety management are } \\
\text { summarized systematically }\end{array}$ & $\begin{array}{l}\text { Lack of research on risk coupling } \\
\text { mechanism and quantitative calculation }\end{array}$ & Aviation safety \\
\hline The SD Model & $\begin{array}{c}\text { The mechanism of risk coupling is deeply } \\
\text { studied }\end{array}$ & Lack of quantitative calculation & Risk management \\
\hline $\begin{array}{l}\text { Interpretative structural } \\
\text { model }\end{array}$ & $\begin{array}{l}\text { Quantitative analysis of interactions in } \\
\text { complex systems }\end{array}$ & $\begin{array}{l}\text { Depending on the subjective judgment of } \\
\text { the decision maker }\end{array}$ & $\begin{array}{l}\text { Business } \\
\text { management }\end{array}$ \\
\hline The N-K model & $\begin{array}{l}\text { Quantitative analysis of the interaction } \\
\text { effects of different components }\end{array}$ & Lack of complete historical data & $\begin{array}{l}\text { Traffic safety } \\
\text { management }\end{array}$ \\
\hline
\end{tabular}

However, in actual application, the accuracy of SD needs to be continuously tested, revised, and improved through practice to adapt to new changes.

\subsubsection{Establishment of Risk Coupling Model Based on the SD} Model. The purpose of the SD model is to divide the whole system into different subsystems and solve complex problems for practical applications. Considering the complexity of the subway construction safety risk system, this paper will establish a safety risk coupling model for the subway shield zone tunnel construction based on the SD model. The following three categories are divided specifically.

Single-factor risk coupling refers to the risk factor affecting the safety of construction in the subway shield zone tunnel, which including multiple interacting subrisk factors. It mainly includes human factor risk coupling, equipment factor risk coupling, environmental factor risk coupling, and management factor risk coupling.

Two-factor risk coupling refers to the mutual influence between two risk factors that affect subway construction safety. It mainly includes the risk coupling of human and equipment, human and environment, human and management, equipment and environment, equipment and management, and environment and management factors.

Multiple-factor risk coupling refers to the interaction of three or more risk factors affecting subway construction safety. It mainly includes the risk coupling of human, equipment, and environmental factors, the risk coupling of human, equipment, and management factors, the risk coupling of equipment, environmental, and management factors, and the risk coupling of human, equipment, environmental, and management factors. The four-factor risk coupling diagram is drawn by establishing positive coupling chain and causal loop, as shown in Figure 3.

3.3. Data Processing. Cloud model is proposed by Deyi Li which is used to deal with the uncertain transformation model of qualitative concepts and quantitative descriptions [38]. Cloud generator refers to the generation algorithm of the cloud model that is modularized by software, which establishes the mapping relationship between qualitative and quantitative [39]. It mainly includes normal cloud generator, reverse cloud generator, $X$-conditional cloud generator, and $Y$-conditional cloud generator.

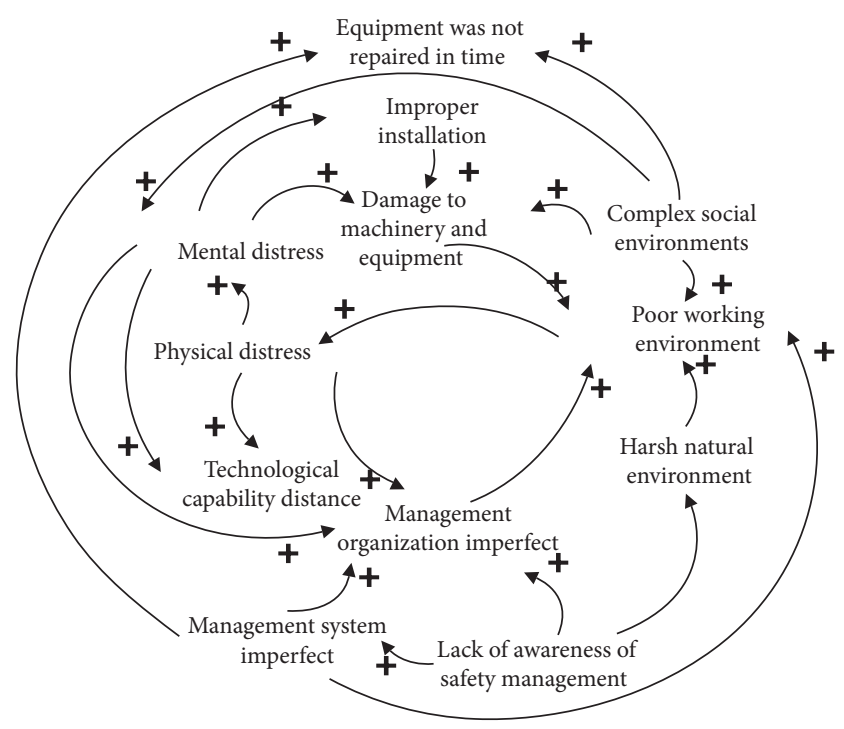

FIGURE 3: Four-factor risk coupling relationship.

Reverse cloud generator is a mapping from quantitative values to qualitative concepts, which can effectively transform data into digital characteristics (expectation, entropy, and hyperentropy). Among them, expectation $\left(E_{x}\right)$ is the cloud droplets that represent qualitative concept the most and is the most typical sample of this concept quantification. Entropy $\left(E_{n}\right)$ is a measurement of the randomness of the qualitative concept, which reflects discrete degree of cloud droplets of this qualitative concept. Hyperentropy $\left(H_{e}\right)$ is the uncertainty measurement of $E_{n}$, which is determined by the randomness and fuzziness of $E_{n}$. At the same time, $H_{e}$ reflects the condensation degree of cloud droplets as well, which can be gained by experience or experiment; the lower the $H_{e}$, the smaller the thickness of the cloud and vice versa. It is worth noting that the transformation process of the backward cloud generator algorithm is reverse and indirect, and errors are inevitable. Therefore, in the process of transformation, when sample variance $\left(S^{2}\right)<$ square of entropy $\left(E_{n}^{2}\right)$, that is, when numerical characteristics $\left(H_{e}^{2}\right)<0$, the most discrete data should be eliminated to ensure that the follow-up formula can draw a conclusion smoothly. The specific algorithm of the backward cloud generator is given in Algorithm 1.

Normal cloud generator is a mapping from qualitative concept to quantitative value, which can transform numerical features into cloud droplets. The degree of data 
Input: sample $X_{i}(i=1,2, \ldots, n)$

Output: numeric characteristics $\left(E_{x}, E_{n}, H_{e}\right)$

(1) Calculate sample mean for this set of data based on $X_{i}: X=1 / n \sum_{i=1}^{n} X_{i}$

(2) Calculate expectations: $E_{x}=\bar{X}$

(3) Calculate the entropy value: $E_{n}=\sqrt{\pi / 2}(1 / n) \sum_{i=1}^{n}\left|X_{i}-E_{x}\right|$

(4) Calculate sample variance: $S^{2}=(1 /(n-1)) \sum_{i=1}^{n}\left(X_{i}-\bar{X}\right)^{2}$

(5) Calculate hyperentropy: $H_{\mathrm{e}}=\sqrt{S^{2}-} E_{n}^{2}$

Algorithm 1

dispersion is represented by cloud droplets distribution pattern. MATLAB software is used to check the consistency of data. If the cloud droplets generated are messy, the most discrete data should be eliminated and the digital characteristics should be recalculated. Repeat this operation until the droplet tends to be stable. Then, a set of effective data can be determined through the cloud model. The objectivity and consistency of data processing are guaranteed by this method. The specific algorithm of the normal cloud generator is given in Algorithm 2 [40].

\subsection{Determination of Index Weight}

3.4.1. Selection of Methods. The multi-index comprehensive evaluation can select corresponding evaluation forms according to different evaluation purposes. Based on the different calculation methods of weights, the multi-index comprehensive evaluation methods can be divided into two categories: subjective weight evaluation method and objective weight evaluation method. Subjective weight evaluation method adopts the qualitative method. Experts make a subjective judgment based on experience to obtain weights, and then make comprehensive evaluation on indexes, such as analytic hierarchy process, comprehensive scoring method, fuzzy evaluation method, index weighting method, and efficacy coefficient method. The objective weighted evaluation method determines the weight according to the relationship between indicators or coefficient of variation and carries out comprehensive evaluation, such as entropy method, neural network analysis method, TOPSIS method, gray correlation analysis method, principal component analysis method, and coefficient of variation method.

Entropy is a basic and important concept in information theory. It can be used to describe the uncertainty degree of the probability distribution. Fuzzy entropy, which is used to describe the degree of fuzziness of a fuzzy set, can be obtained by transplanting the concept of entropy to fuzzy set theory. The greater the fuzzy entropy is, the more blurred the fuzzy set is and vice versa. In the feature set, the fuzzy entropy of each feature can be calculated. For a certain feature, the greater its fuzzy entropy, the greater its uncertainty, indicating that the values of this feature variable are scattered, which are more conducive to be classified.

The advantages of fuzzy entropy are as follows:

(1) When the index system is qualitative, it can eliminate the interference of the weight proportion of subjective or objective conditions and the subjectivity of evaluation methods

(2) It ensures that the fuzzy entropy does not change abruptly and that the self-similarity of the vector is maximized

However, the common characteristics of quantitative and qualitative empowerment need to be considered when calculating weight by using this fuzzy entropy, which makes the actual operation more difficult.

3.4.2. Fuzzy Entropy Theory. In order to reveal risks completely, fuzzy entropy theory is used to avoid subjective evaluation results and to establish the weights of various indicators. First, five classes are divided based on the influence degree of risk indicators on subway tunnel construction: Class $\mathrm{I} \in[0,0.2)$ indicates slight, Class $\mathrm{II} \in[0.2$, $0.4)$ indicates relatively slight, Class III $\in[0.4,0.6)$ indicates moderate, Class IV $\in[0.6,0.8)$ indicates more serious, and Class $\mathrm{V} \in[0.8,1)$ indicates severe. The weight of risk indicators can be determined by following $E_{q}[41,42]$.

(1) The risk grade of each data is divided, and the membership matrix $\left(r_{i j k}\right)$ is obtained based on fuzzy entropy theory:

$$
\begin{aligned}
r_{i j k} & =\frac{x_{i j k}}{P}, \quad k=1,2,3, \ldots, m, 0 \leq r_{i j k} \leq 1, \\
E_{i j} & =-\frac{1}{\ln m} \sum_{k=1}^{m} r_{i j k} \cdot \ln r_{i j k}, \\
W_{\mathrm{ij}} & =\frac{1-E_{i j}}{\sum_{j=1}^{n} 1-E_{i j}}, \\
r_{i k} & =\sum_{i=1}^{n} r_{i j k} \cdot w_{i j}, \\
\left(\begin{array}{c}
R_{1} \\
\vdots \\
R_{i}
\end{array}\right) & =\left(\begin{array}{ccc}
r_{11} & \ldots & r_{1 m} \\
\vdots & \ldots & \vdots \\
r_{i 1} & \ldots & r_{i m}
\end{array}\right),
\end{aligned}
$$

where $k=1,2, \ldots, m, m$ is the evaluation level, $i$ is the 1st-level indicator number, and $j$ is the 2 nd-level indicator number of the corresponding 1st-level 
Input: numeric characteristics $\left(E_{x}, E_{n}, H_{e}\right)$, the number of cloud droplets is $n$

Output: $n$ cloud droplet points $\left(x_{n}, u_{n}\right)$

(1) Generate a normal random number $\left(E_{n}\right)$ with $E_{n}$ as the expected value and $H_{e}$ as the standard deviation

(2) Generate a normal random number with $E_{x}$ as the expected value and $E_{n}$ as the standard deviation

(3) Calculate the formula: $u_{n}=\exp \left(-\left(x_{n}-E_{x}\right)^{2} / 2\left(E_{n}^{\prime}\right)^{2}\right)$

(4) Repeat steps (1)-(3) $n$ times to obtain a cloud droplets diagram including $n$ cloud droplets

Algorithm 2

indicators. $p$ is the number of experts, $r_{i j k}$ equals the degree of membership of the 2nd-level indicator $C_{i j}$ relative to the k-level risk. $x_{i j k}$ represents the total number of experts who assess the 2 nd-level indicator $C_{i j}$ as k-level risk, $r_{i j k}$ is the degree of membership of the 1st-level indicator $C_{i}$ relative to the k-level risk, $n$ is the number of the 2 nd-level indicators in the 1 stlevel indicators, and $w_{i j}$ is the weight of 2 nd-level indicator $C_{i j}$.

(2) Calculation of information entropy $H_{i}$ :

The information entropy is a measurement of system disorder degree. This information is a measurement of system order degree, and its algebraic sum of them is zero. According to variation of each index, the weight of each index is calculated by information entropy. The calculation equation of the information entropy $H_{i}$ is as follows:

$$
H_{i}=-\sum_{k=1}^{m} r_{i k} \ln r_{i k} \text {. }
$$

(3) Calculation of output entropy $E_{i}$ :

When $r_{i k}$ is equal, information entropy is maximum, that is, $H_{\max }=\ln _{m}$, and it is used to get output entropy $E_{i}$, which is the measurement of the importance of $C_{i} . E_{i}=[0,1]$, and when $E_{i}$ is maximum, the contribution of this factor to the evaluation of the system is minimal. The formula for the calculation of the output entropy $E_{i}$ is as follows:

$$
E_{i}=-\frac{1}{\ln m} \sum_{k=1}^{m} r_{i k} \ln r_{i k}=\frac{H_{i}}{\ln m} \text {. }
$$

(4) Calculation of difference degree $G_{i}$ :

When the values of all membership $r_{i k}$ are equal, the value of the maximum output entropy $E_{i}$ is equal to 1 , that is, $0 \leq E_{\mathrm{i}} \leq 1$. When the value of the output entropy is the maximum, the value of the factor's contribution to the system assessment is the minimum; the weight of $C_{i}$ can be determined by the difference degree $G_{i}$ :

$$
G_{i}=1-E_{i}
$$

(5) Calculation of weight $W_{i}$ :

$$
W_{i}=\frac{G_{i}}{\sum_{i=1}^{n} G_{i}} .
$$

Based on the digital characteristics and weights of the 2nd-level indicators, the digital characteristics of the 1st-level indicators $\left(E_{x}, E_{n}, H_{e}\right)$ can be determined by the following formulas:

$$
\begin{aligned}
E_{x}= & \frac{\sum_{i=1}^{m} E_{x i} w_{i}}{\sum_{i=1}^{m} w_{i}}, \\
E_{n}= & \frac{w_{1}^{2}}{\sum_{i=1}^{m} w_{i}^{2}} E_{n 1}+\frac{w_{2}^{2}}{\sum_{i=1}^{m} w_{i}^{2}} E_{n 2} \\
& +\ldots+\frac{w_{i}^{2}}{\sum_{i=1}^{m} w_{i}^{2}} E_{n m}, \\
H_{e}= & \frac{w_{1}^{2}}{\sum_{i=1}^{m} w_{i}^{2}} H_{e 1}+\frac{w_{2}^{2}}{\sum_{i=1}^{m} w_{i}^{2}} H_{e 2} \\
& +\ldots+\frac{w_{i}^{2}}{\sum_{i=1}^{m} w_{i}^{2}} H_{e m} .
\end{aligned}
$$

3.5. Establishment of the Expected Utility Function. Suppose that $i$ is the order parameter of a risk system, the expected utility function formula of the 2nd-level risk indicator is as follows:

$$
U_{i j}=\frac{\left(E_{x i j}-B_{i j}\right)}{\left(A_{i j}-B_{i j}\right)},
$$

where $E_{x i j}$ is the expectation value of the $j$-th indicator of the $i$-th parameter in the construction risk system of the subway shield zone tunnel. $A_{i j}$ and $B_{i j}$ are the upper and lower limits of this indicator, respectively. The efficiency value is $U_{i j} \in[0,1]$, which reflects the contribution of each indicator to risk coupling. The closer $U_{i j}$ gets to 0 , the less contribution it makes; the closer $U_{i j}$ gets to 1 , the greater contribution it makes. The efficacy value of the 1 st-level risk indicator can be achieved through the following formula:

$$
U_{i}=\sum_{j=1}^{m} U_{i j} w_{i j}
$$

3.6. Establishment of the Coupling Degree Function. At present, the research on coupling degree is mainly used in the fields of computer and urban development, and the risk coupling is mainly used in air traffic safety and rail traffic operation, but it has not been involved in rail traffic construction, especially in the subway shield zone tunnel construction. In this paper, the coupling degree study will be carried out for the safety risks of the subway shield zone tunnel construction. Methods of coupling degree analysis 
mainly include coupling degree model, N-K model, explanation structure model, and nonlinear dynamic model. The $\mathrm{N}-\mathrm{K}$ model can only be used to analyze the target model after collecting a large amount of historical data. The explanatory structural model can be used to qualitatively analyze the primary and secondary hierarchical relationships among elements but cannot be used to quantitatively calculate the coupling degree. The nonlinear dynamic model can only be used to analyze the coupling degree of two subsystems.

Compared with the other three models, the advantage of the coupling degree model is that the quality requirement of the sample is not high and the calculation is simple, which can be used to realize quantitative analysis of coupling among multiple risk factors and understand the coupling state of the system.

The disadvantage is that this method needs to use the expert scoring method to obtain quantitative information, which has limitations.

Considering the limitation of sample size, this paper uses the coupling degree model to analyze the coupling degree of risk factors and the cloud model to improve the accuracy of data processing to reduce the influence of subjective factors. The coupling degree model calculating the risk coupling degree is obtained by the following formula:

$$
C_{m}=\left\{\frac{\left(U_{1} \cdot U_{2} \cdot U_{3} \cdots U_{m}\right)}{\left[\prod\left(U_{i}+U_{j}\right)\right]}\right\}^{1 / m},
$$

where $m$ is the number of risk indicators. When $C \in[0,1]$, the coupling state is divided into four grades according to physics. Grade 1 : when $C \in[0,0.3)$, it is a low level of risk coupling. The risk coupling movement has little destructive effect on the security defense system, but its destructive power can be expanded at any time. Grade 2: when $C \in[0.3,0.5)$, it is a moderate level of risk coupling. The destructive power of risk coupling movement is enhanced, and these risk factors are in the stage of antagonism and running-in. Among them, a small number of risks could break through the security defense system, and the destructive power of the original risks can be enhanced, which means new risks can be triggered at any time. Grade 3: when $C \in[0.5,0.7)$, it is a higher level of risk coupling. The risk coupling movement has great destructive power, and these risk factors are in a state of fierce antagonism and runningin. Among them, most of these risks could break through the security defense system and new risks can be triggered. Grade 4 : when $C \in[0.7,1]$, it is a high level of risk coupling. The security defense system has been completely broken, and the risk coupling movement will undergo qualitative change and form a new coupling risk.

\section{Empirical Analysis}

4.1. Engineering Background. The shield zone tunnel at both ends of the station (Cultural Center Station) of Tianjin subway Line 5 and Line 6 is shown in Figure 4. The project consists of three parts, Cultural Center Station to Hotel West Road Station subway shield zone tunnel, Hotel West Road Station to Cultural Center Station subway shield zone tunnel, and Cultural Center Station to Canton Road Station subway shield zone tunnel.

The inner diameter of this shield tunnel is $\Phi 5500 \mathrm{~mm}$, the outer diameter is $\Phi 6200 \mathrm{~mm}$, and the lining is $350 \mathrm{~mm}$. The lining segment is made of prefabricated reinforced concrete and is assembled by staggered technology. Its duct piece is connected by bending bolts. Four Earth pressure balance shield machines are adopted in tunnel construction.

\subsection{Calculation Steps and Results}

Step 1. Experts concerned are invited to grade the marking table. First, based on the characteristics of all levels of indicators and the actual situation of subway engineering, the expert marking table is formulated, as shown in Table 4 . Then, 50 experts were invited to grade the marking table, and the average age of experts was between 28 and 55 years old. Among them, 20 experts and scholars are majored in subway construction risks. 6 professors, associate professors and professional teachers, are majored in civil engineering of Southwest University of Petroleum and have more than 10 years of teaching experience and a deep understanding of the industry's frontiers. 4 professional teachers, majors in tunnel engineering of Southwest Jiaotong University and 3 professional teachers, majors in engineering management of Sichuan University of Science and Technology, have more than five years of teaching experience. 4 experts majored in tunnel and underground engineering of China Railway Eryuan Engineering Group Co. Ltd and 3 experts majored in tunnel engineering of Tianjin Urban Construction Group have more than five-ten years of experience in this field. 20 engineers and 10 construction workers engaged in subway projects are mainly from China Railway Tunnel Group, China Railway 18 Bureau Group, and Fourth Engineering of China Railway First Group. Most of the engineers have bachelor's degree and have worked in this field for 5-8 years, and the constructors have been engaged in subway tunnels for 310 years and have rich construction experience. The experts mentioned above include theoretical and practical research representatives in order to ensure scientific data sources.

The specific steps are as follows: (1) according to the index system, a marking table is made, which contains the marking rules of the comprehensive index system of the subway shield zone tunnel construction safety risk system and the risk classification for evaluation indexes. (2) The specific meaning of each index in the marking table is explained to the personnel concerned and then distributed it to other experts of the unit and explained the specific meaning. Finally, 43 marking tables were collected and 41 were valid.

Step 2. Data processing: data are processed according to Algorithm 1 of the reverse cloud generator and the rule of data processing. The specific steps are as follows: (1) digital characteristics $\left(E_{x}, E_{n}, H_{e}\right)$ are computed in Excel software. (2) The evaluation data of 20 experts are selected from the 50 experts scoring database. This model has no special requirement to the expert number, and it can be selected proportionally from the collected database. But, the ratio 


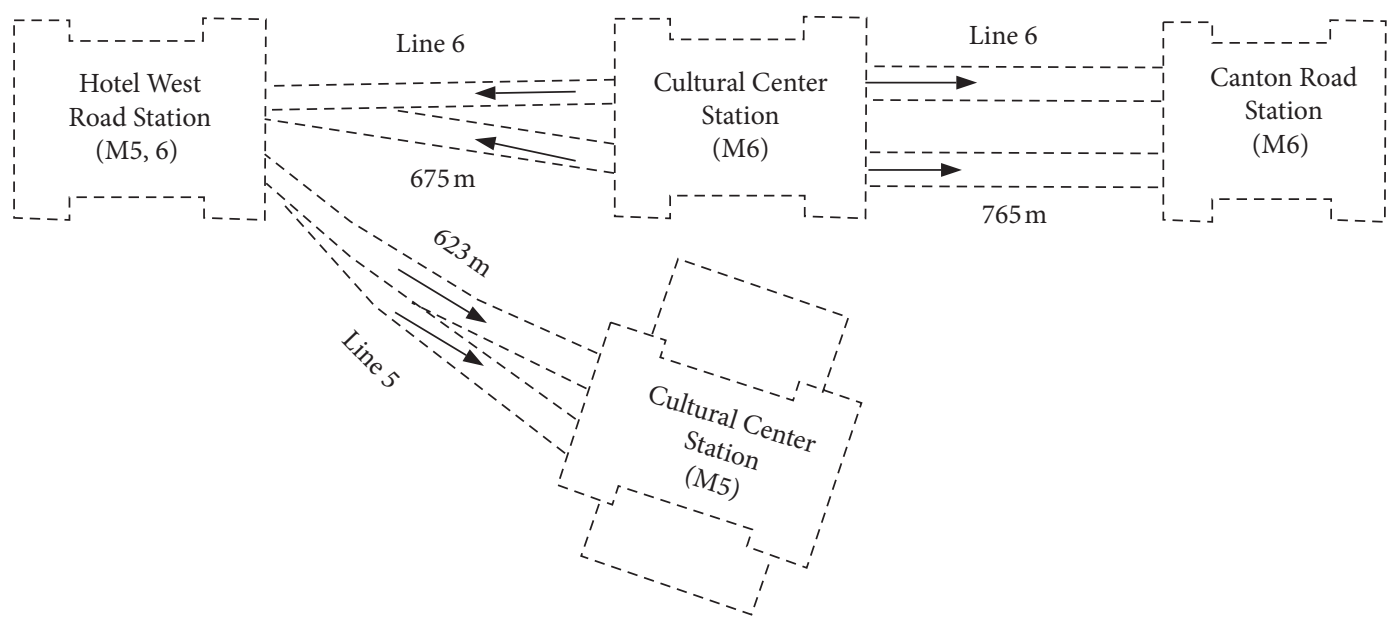

Figure 4: The plan diagram of this subway project.

TABLE 4: Marking table.

\begin{tabular}{|c|c|c|c|}
\hline The 1st-level indicators & The 2nd-level indicators & Evaluation rule & Score range \\
\hline \multirow{3}{*}{ Human risk factors } & Physiological factors & $\begin{array}{l}\text { According to the records of construction log and } \\
\text { relevant work experience of raters, raters should } \\
\text { comprehensively judge the degree of influence of the } \\
\text { physiological condition of constructors (such as } \\
\text { drunk, fatigue, and sick) on construction of the } \\
\text { subway shield zone tunnel. }\end{array}$ & {$[0,1]$} \\
\hline & Mental factors & $\begin{array}{l}\text { According to records of safety management training } \\
\text { and relevant work experience of raters, raters should } \\
\text { comprehensively judge the degree of influence of the } \\
\text { psychology state of constructors (such as safety } \\
\text { awareness, responsibility, and attention) on } \\
\text { construction of the subway shield zone tunnel. }\end{array}$ & {$[0,1]$} \\
\hline & Technical factors & $\begin{array}{l}\text { According to archival information of the constructor } \\
\text { and relevant work experience of raters, raters should } \\
\text { comprehensively judge the degree of influence of the } \\
\text { technical operational level of constructors (such as } \\
\text { practicing certificates, inexperience, and operational } \\
\text { capacity) on construction of the subway shield zone } \\
\text { tunnel. }\end{array}$ & {$[0,1]$} \\
\hline \multirow{3}{*}{ Machinery risk factors } & Improper installation & $\begin{array}{l}\text { According to mechanical installation management } \\
\text { system and relevant work experience of raters, raters } \\
\text { should comprehensively judge the degree of influence } \\
\text { of improper mechanical installation on construction } \\
\text { of the subway shield zone tunnel. }\end{array}$ & {$[0,1]$} \\
\hline & Machinery fault & $\begin{array}{l}\text { According to mechanical security management } \\
\text { system and relevant work experience of raters, raters } \\
\text { should comprehensively judge the degree of influence } \\
\text { of machinery fault on construction of the subway } \\
\text { shield zone tunnel. }\end{array}$ & {$[0,1]$} \\
\hline & Machines in disrepair & $\begin{array}{l}\text { According to mechanical security management } \\
\text { system and relevant work experience of raters, raters } \\
\text { should comprehensively judge the degree of influence } \\
\text { of machines in disrepair on construction of the } \\
\text { subway shield zone tunnel. }\end{array}$ & {$[0,1]$} \\
\hline
\end{tabular}


TABLE 4: Continued.

\begin{tabular}{|c|c|c|c|}
\hline The 1st-level indicators & The 2nd-level indicators & Evaluation rule & Score range \\
\hline \multirow{3}{*}{ Environmental risk factors } & Natural environment factors & $\begin{array}{l}\text { According to geological prospecting data and } \\
\text { relevant work experience of raters, raters should } \\
\text { comprehensively judge the degree of influence of } \\
\text { natural environment (such as geological conditions } \\
\text { and hydrological conditions) on construction of the } \\
\text { subway shield zone tunnel. }\end{array}$ & {$[0,1]$} \\
\hline & Working environment factors & $\begin{array}{l}\text { According to records of construction log and relevant } \\
\text { work experience of raters, raters should } \\
\text { comprehensively judge the degree of influence of } \\
\text { working environment (such as working space and } \\
\text { working conditions) on construction of the subway } \\
\text { shield zone tunnel. }\end{array}$ & {$[0,1]$} \\
\hline & Social environment factors & $\begin{array}{l}\text { According to feasibility report of the project and } \\
\text { relevant work experience of raters, raters should } \\
\text { comprehensively judge the degree of influence of } \\
\text { social environment (such as economy, labor force, } \\
\text { construction market, and national policy) on } \\
\text { construction of the subway shield zone tunnel. }\end{array}$ & {$[0,1]$} \\
\hline \multirow{3}{*}{ Management risk factors } & Management mechanism factors & $\begin{array}{l}\text { According to the integrity and effectiveness of the } \\
\text { current management mechanism and relevant work } \\
\text { experience of raters, raters should comprehensively } \\
\text { judge the degree of influence of management } \\
\text { mechanism (such as emergency management, daily } \\
\text { management, and performance assessment) on } \\
\text { construction of the subway shield zone tunnel. }\end{array}$ & {$[0,1]$} \\
\hline & Management organization factors & $\begin{array}{l}\text { According to the integrity and effectiveness of the } \\
\text { current management mechanism and relevant work } \\
\text { experience of raters, raters should comprehensively } \\
\text { judge the degree of influence of the management } \\
\text { mechanism (such as management capacity of the } \\
\text { project manager and imperfect management } \\
\text { organization) on construction of the subway shield } \\
\text { zone tunnel. }\end{array}$ & {$[0,1]$} \\
\hline & Safety management system & $\begin{array}{l}\text { According to implementation of the current security } \\
\text { management system and relevant work experience of } \\
\text { raters, raters should comprehensively judge the } \\
\text { degree of influence of the safety management system } \\
\text { (such as safety training of employees and } \\
\text { construction site safety management) on } \\
\text { construction of the subway shield zone tunnel. }\end{array}$ & {$[0,1]$} \\
\hline
\end{tabular}

Note: the influence degree of safety risk indicators on subway tunnel construction is divided into five class: Class I $\in[0,0.2)$ indicates slight, Class II $\epsilon[0.20 .4)$ indicates relatively slight, Class II $\in\left[\begin{array}{ll}0.4 & 0.6\end{array}\right)$ indicates moderate, Class IV $\in\left[\begin{array}{ll}0.6 & 0.8\end{array}\right)$ indicates more serious, and Class $\mathrm{V} \in\left[\begin{array}{lll}0.8 & 1\end{array}\right]$ indicates severe.

of academic experts, engineers, and construction workers should be 2: 2: 1 , and the scores of the remaining experts are entered in the candidate database. (3) Enter these data in Excel software and convert them into a set of digital characteristics $\left(E_{x}, E_{n}, H_{e}\right)$. (4) Checking data, when sample variance $\left(S^{2}\right)$ $<$ square of entropy $\left(E_{n}^{2}\right)$, the most discrete data should be eliminated. Eliminated discrete data should be replaced by evaluation data from the same type of experts from the alternative database to ensure 20 evaluation data are calculated at a time. (5) Repeat step (3) until the value of $H_{e}^{2}$ is greater than 0.

Based on the normal cloud generator algorithm, the consistency of data is further checked. The steps are as follows: (1) MATLAB code has been programmed in this paper, which is used to convert the digital characteristics of the 2nd-level indicators to 1000-cloud droplets diagram. (2)
Observe the condensation degree of cloud droplets and eliminate the more discrete data. (3) The new evaluation data are added from the candidate database, and the calculation step of the reverse cloud generator is repeated until the cloud droplets diagram tends to be stable, and the data screening process is completed. The screening process is shown in Figures 5 and 6, and part of cloud droplets is shown in Figures 7-10. The digital characteristics $\left(E_{x}, E_{n}, H_{e}\right)$ of the 2nd-level indicators are calculated in Table 5.

\section{Step 3. Determination of index weight:}

(1) The expert evaluation data are classified according to the risk level, and the evaluation results are shown in Table 6 


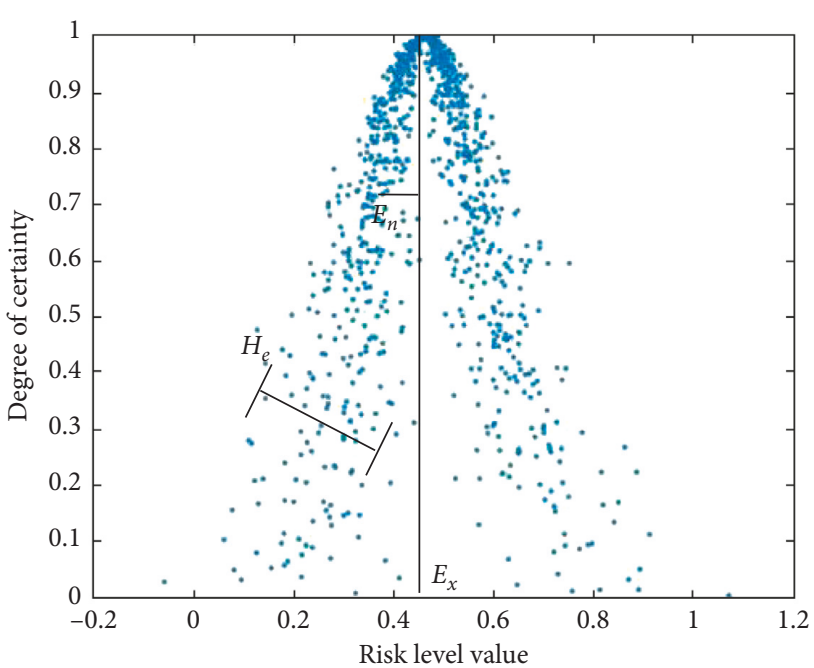

Figure 5: Discrete cloud drop diagram.

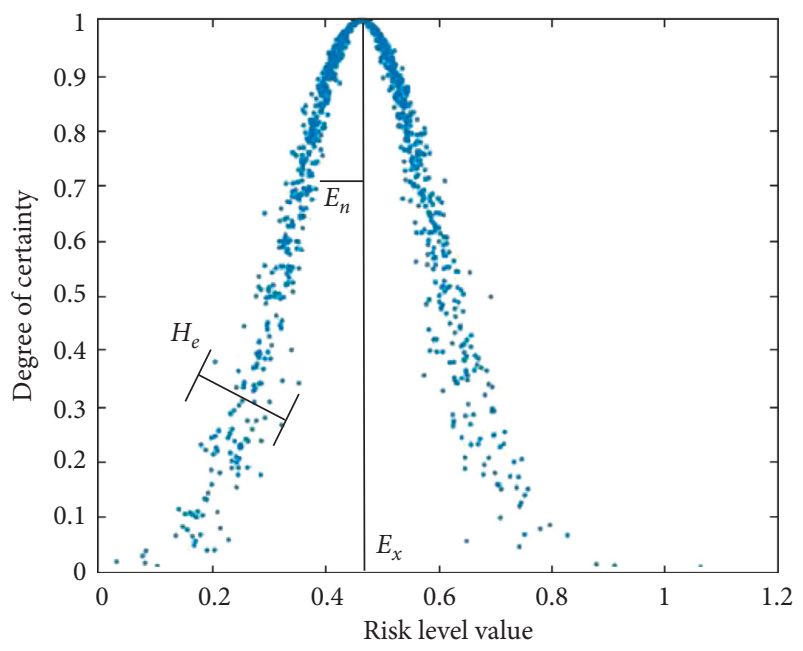

Figure 6: Condensed cloud drop diagram.

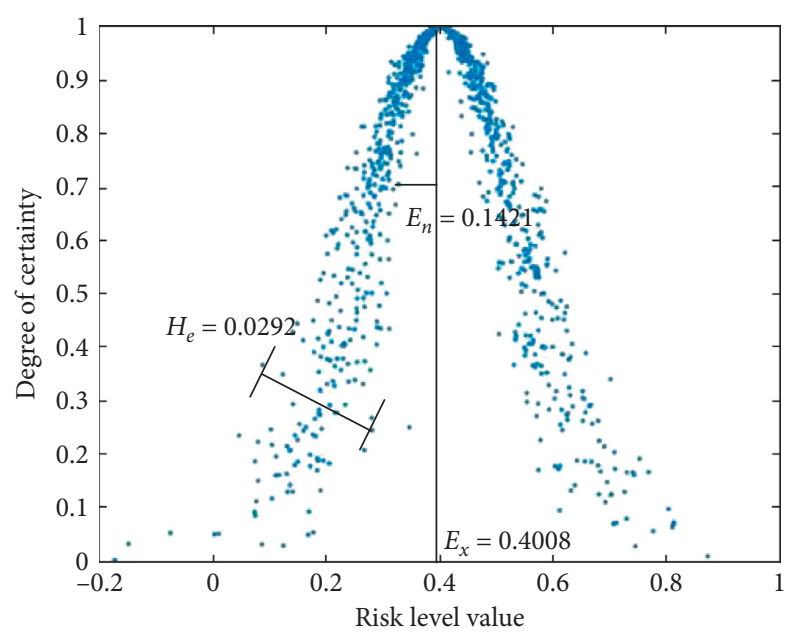

Figure 7: Human factors cloud drop diagram.

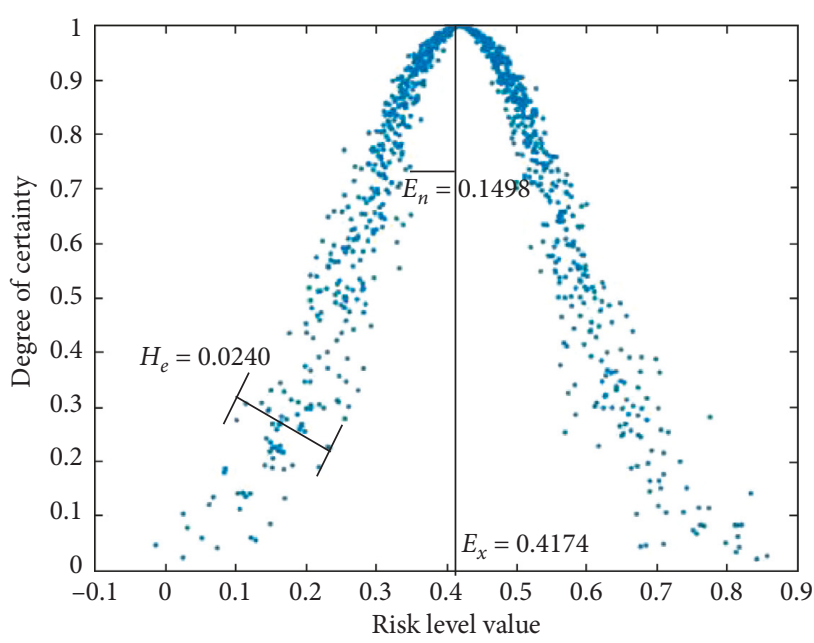

Figure 8: Machinery factors cloud drop diagram.

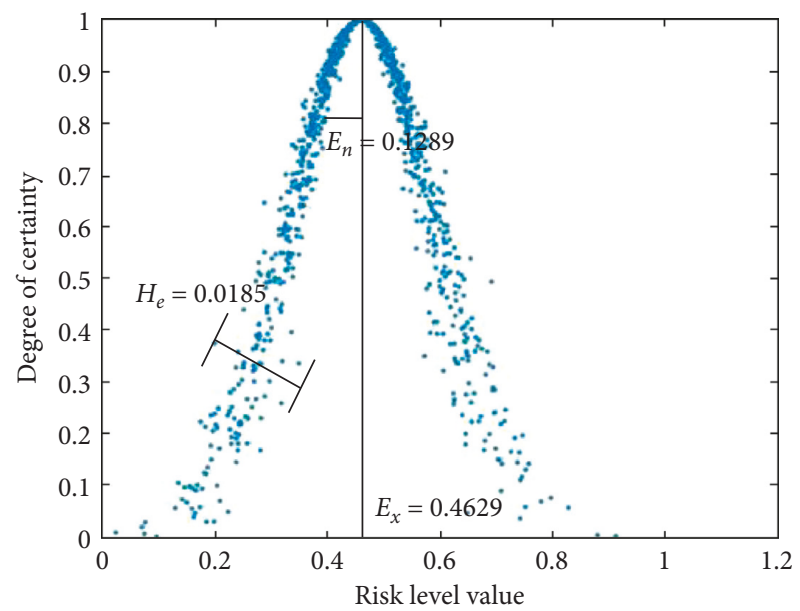

FIgURE 9: Environment factors cloud drop diagram.

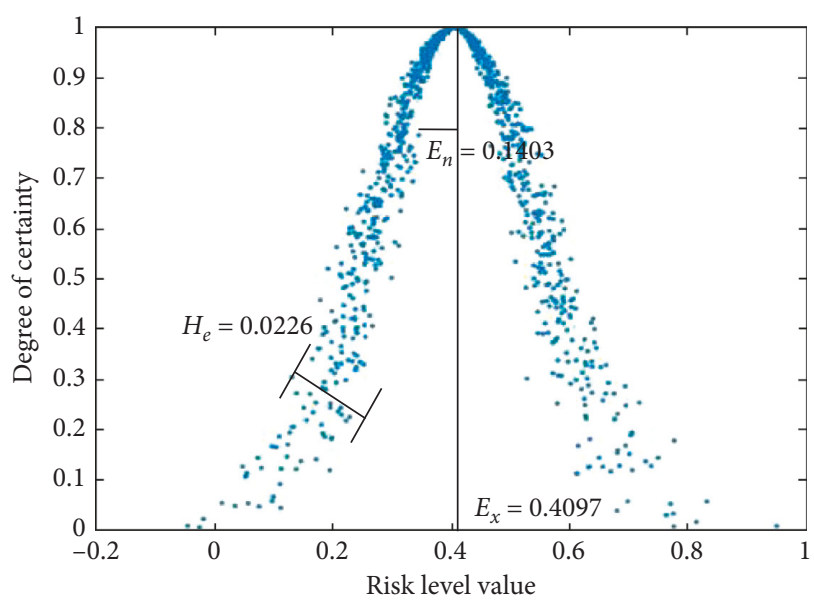

Figure 10: Management factors cloud drop diagram. 
TABLE 5: The digital characteristics of 2nd-level indicators.

\begin{tabular}{lccr}
\hline The 2nd-level indicators & $E_{x}$ & $E_{n}$ & $H_{e}$ \\
\hline Physiological factors R11 & 0.3250 & 0.1504 & 0.0501 \\
Mental factors R12 & 0.4300 & 0.1416 & 0.0070 \\
Technical factors R13 & 0.4350 & 0.1360 & 0.0424 \\
Improper installation R21 & 0.4700 & 0.1918 & 0.0133 \\
Machinery fault R22 & 0.4200 & 0.1328 & 0.0296 \\
Machines in disrepair R23 & 0.4050 & 0.1592 & 0.0207 \\
Natural environment factors R31 & 0.5300 & 0.1241 & 0.0605 \\
Working environment factors R32 & 0.4900 & 0.1166 & 0.0561 \\
Social environment factors R33 & 0.3600 & 0.1479 & 0.0256 \\
Management mechanism factors R41 & 0.3850 & 0.1335 & 0.0192 \\
Management organization factors R42 & 0.4050 & 0.1460 & 0.0153 \\
Safety management system R43 & 0.4400 & 0.1379 & 0.0376 \\
\hline
\end{tabular}

(2) Calculating index weight. The specific steps are as follows:

(a) The matrix of the membership degrees of the 2nd-level indicators is calculated by formula (1)

Taking R1 as an example, the matrix of the membership degrees is as follows:

$$
R_{1}=\left(\begin{array}{ccccc}
0.3 & 0.5 & 0.15 & 0.05 & 0 \\
0.05 & 0.5 & 0.3 & 0.05 & 0 \\
0.05 & 0.5 & 0.35 & 0.1 & 0
\end{array}\right)
$$

(b) According to formulas (2) and (3), the normalized 2nd-level indicator weight is obtained: $W_{11}=0.2936$, $W_{12}=0.3805$, and $W_{13}=0.3259$. The weight of other 2nd-level indicators can be obtained from the aforementioned steps, and the matrix of the membership degrees of the 1st-level indicators is calculated by formulas (4) and (5) as follows:

$$
R=\left(\begin{array}{ccccc}
0.12 & 0.50 & 0.31 & 0.07 & 0 \\
0.07 & 0.58 & 0.26 & 0 & 0 \\
0.07 & 0.34 & 0.44 & 0.15 & 0 \\
0.08 & 0.54 & 0.32 & 0.07 & 0
\end{array}\right)
$$

(c) The weights of risk indicators at all levels are calculated by formulas (6)-(9). The calculation results are shown in Table 7.

(3) The digital characteristics of the 1st-level indicators are obtained by formulas $(10) \sim(12)$, as shown in Table 8.

Step 4. Calculate efficacy value and coupling degree value.

(1) The efficacy value of risk indicators at all levels is calculated by formulas (13) and (14). The upper and lower limits of the comprehensive index represent the ideal or minimum values of the system. In this study, the upper and lower limits of indicators will be confirmed by the influence degree of safety risk indicators on subway tunnel construction, namely, $A_{i j}=1$ and $B_{i j}=0$. The result is shown in Table 9 .
(2) The coupling degree between various safety risk factors and the whole safety risk system are calculated by formula (15), and the results are shown in Table 10 .

\subsection{Result Analysis and Preventive Measures}

\subsubsection{Result Analysis}

(1) In the coupling degree model, the greater the efficacy value of these indicators, the greater the contribution to the degree of coupling of the security risk systems. As can be seen from Table 9, the environmental risk factor $\left(R_{3}=0.4629\right)$ has the highest performance value among the first-level indicators and the greatest damage to the system. Therefore, from the perspective of controlling risks, preventive measures should be taken to control environmental risk factors in order to prevent the occurrence of safety accidents. The efficacy value of $R_{13}, R_{21}, R_{31}$, and $R_{43}$ is the highest in second-level indicators, which has the largest contribution and is the easiest to destroy the safety risk system coupled with other risk factors. In the 101 safety risk accidents, there were 48 ground collapse accidents. As can be seen from Table 1, the causes of ground collapse accidents include human risk factors (inexperience and incompetence, namely, $R_{13}$ ), machinery risk factors (machinery fault and improper installation, namely, $R_{21}$ ), environmental risk factors (complex geological and operating environment, namely, $R_{31}$ ), and management risk factors (unsound safe management system, namely, $R_{43}$ ). This matches well with the calculation results of the model.

(2) As can be seen from Table 10, the value of risk coupling degree of two factors is $C_{2} \in[0.4987,0.5000]$, in which the coupling value of human and management risk factors $(C=0.5000)$ is the highest. When personnel and management risk factors are coupled, they are most destructive. At this time, the development state of the security risk system is in a medium level of risk coupling, and the system is in a relatively balanced development state. However, new risks could be triggered at any time by the two risk factors constantly 
TABLE 6: Initial evaluation form for expert evaluation data.

\begin{tabular}{|c|c|c|c|c|c|c|}
\hline \multirow{2}{*}{$R_{i}$} & \multirow{2}{*}{$R_{i j}$} & \multicolumn{5}{|c|}{ Class of risk } \\
\hline & & I & II & III & IV & $\mathrm{V}$ \\
\hline \multirow{3}{*}{$\mathrm{R} 1$} & R11 & 6 & 10 & 3 & 1 & 0 \\
\hline & $\mathrm{R} 12$ & 1 & 10 & 8 & 1 & 0 \\
\hline & $\mathrm{R} 13$ & 1 & 10 & 7 & 2 & 0 \\
\hline \multirow{3}{*}{$\mathrm{R} 2$} & $\mathrm{R} 21$ & 2 & 7 & 8 & 2 & 1 \\
\hline & R22 & 2 & 11 & 6 & 1 & 0 \\
\hline & $\mathrm{R} 23$ & 1 & 13 & 4 & 2 & 0 \\
\hline \multirow{3}{*}{ R3 } & R31 & 1 & 2 & 13 & 4 & 0 \\
\hline & R32 & 0 & 7 & 9 & 4 & 0 \\
\hline & R33 & 3 & 12 & 4 & 1 & 0 \\
\hline \multirow{3}{*}{$\mathrm{R} 4$} & R41 & 3 & 11 & 5 & 1 & 0 \\
\hline & $\mathrm{R} 42$ & 1 & 12 & 6 & 1 & 0 \\
\hline & $\mathrm{R} 43$ & 1 & 9 & 8 & 2 & 0 \\
\hline
\end{tabular}

TABLE 7: The weight of risk indicators.

\begin{tabular}{lccc}
\hline The 1st-level indicators & $W_{i}$ & The 2nd-level indicators & $W_{i j}$ \\
\hline Human risk factors R1 & & Physiological factors R11 & Mental factors R12 \\
& 0.2310 & Technical factors R13 & 0.2936 \\
& & $\begin{array}{c}\text { Improper installation R21 } \\
\text { Machinery fault R22 }\end{array}$ & 0.3805 \\
\hline & & Machines in disrepair R23 & 0.0976 \\
Machinery risk factors R2 & 0.3011 & Natural environment factors R31 & 0.4023 \\
& & Working environment factors R32 & 0.3566 \\
& & Social environment factors R33 & 0.3250 \\
Environmental risk factors R3 & 0.2200 & Management mechanism factors R41 & 0.3184 \\
& & Management organization factors R42 & 0.3055 \\
& & Safety management system R43 & 0.3868 \\
Management risk factors R4 & 0.2479 & 0.3077 \\
\hline
\end{tabular}

TABLE 8: The digital characteristics of the 1st-level indicators.

\begin{tabular}{lccr}
\hline The 1st-level indicators & $E_{x}$ & $E_{n}$ & $H_{e}$ \\
\hline Human risk factors R1 & 0.4008 & 0.1421 & 0.0292 \\
Machinery risk factors R2 & 0.4174 & 0.1498 & 0.0240 \\
Environmental risk factors R3 & 0.4629 & 0.1289 & 0.0185 \\
Management risk factors R4 & 0.4097 & 0.1403 & 0.0226 \\
\hline
\end{tabular}

confronting and running-in, expanding each other's original risks, and effective measures should be taken to control the occurrence of disasters. However, the coupling value of the three-factor risk coupling has been significantly improved $\left(C_{3} \in[0.5810,0.6108]\right)$. At this time, the risk coupling movement has great destructive power, and these risk factors are in a state of fierce confrontation and running-in. Among them, some risks have broken through the security defense system and could trigger new risks, and the coupling degree values of human-machine-management risk factors and human-environment-management risk factors are 0.6108 and 0.5884 , respectively, which are higher than the values in other two risk coupling modes. It can be seen that the risk of complete coupling between the two subjective factors (human factors and management factors) is greater than the risk of incomplete coupling. Therefore, the effective measures should be taken to prevent the coupling movement of subjective factors in construction.

(3) The four-factor risk coupling degree value of $C_{4}=0.6997$ is in higher level of risk coupling. At this time, the safety risk system is in an unbalanced stage of development, and the coupling movement between the factors has a tremendous destructive effect on the safety risk system of subway shield zone tunnel construction, and the probability of safety risk accidents is expanding. The coupling degree of the four factors is the highest, which has a huge destructive impact on the safety risk system of subway shield zone tunnel construction. Most of the risks have broken through the security defense system, constantly triggering new risks and expanding the original risks. Practically, all risks factors will not be coupled at the same time but running in a fixed risk coupling mode. These risks interact with each other 
TABLE 9: The efficacy value of risk indicators at all levels.

\begin{tabular}{lccc}
\hline The 1st-level indicators & $U_{i}$ & The 2nd-level indicators & $U_{i j}$ \\
\hline Human risk factors R1 & & Physiological factors R11 & Mental factors R12 \\
& 0.4008 & Technical factors R13 & 0.3250 \\
& & Improper installation R21 & 0.4300 \\
& & Machinery fault R22 & 0.4350 \\
Machinery risk factors R2 & 0.4174 & Machines in disrepair R23 & 0.4700 \\
& & Natural environment factors R31 & 0.4050 \\
\hline & & Working environment factors R32 & 0.5300 \\
Environmental risk factors R3 & 0.4629 & Social environment factors R33 & 0.4900 \\
& & Management mechanism factors R41 & 0.3600 \\
\hline & & Management organization factors R42 & 0.3850 \\
Management risk factors R4 & 0.4097 & Safety management system R43 & 0.4050 \\
& & 0.4400 \\
\hline
\end{tabular}

TABLE 10: The results of coupling degree value.

\begin{tabular}{|c|c|c|}
\hline Tape & Risk coupling mode & Value \\
\hline \multirow{6}{*}{ Two-factor risk coupling } & The risk coupling of human and machinery factors & 0.4999 \\
\hline & The risk coupling of human and environment factors & 0.4987 \\
\hline & The risk coupling of human and management factors & 0.5000 \\
\hline & The risk coupling of machinery and environment & 0.4993 \\
\hline & $\begin{array}{c}\text { The risk coupling of machinery and management } \\
\text { factors }\end{array}$ & 0.4999 \\
\hline & $\begin{array}{c}\text { The risk coupling of environment and management } \\
\text { factors }\end{array}$ & 0.4991 \\
\hline \multirow{4}{*}{ Three-factor risk coupling } & $\begin{array}{l}\text { The risk coupling of human, machinery, and } \\
\text { environment factors }\end{array}$ & 0.5849 \\
\hline & $\begin{array}{l}\text { The risk coupling of human, machinery, and } \\
\text { management factors }\end{array}$ & 0.6108 \\
\hline & $\begin{array}{c}\text { The risk coupling of human, environment, and } \\
\text { management factors }\end{array}$ & 0.5884 \\
\hline & $\begin{array}{l}\text { The risk coupling of machinery, environment, and } \\
\text { management factors }\end{array}$ & 0.5810 \\
\hline Four-factor risk coupling & $\begin{array}{l}\text { The risk coupling of human, machinery, } \\
\text { environment, and management factors }\end{array}$ & 0.6997 \\
\hline
\end{tabular}

for further impact and completely break through the risk defense system ultimately and lead to risk accidents. Combined with Table 9, it can be known that in the two-factor risk coupling, the coupling degree between human and management factors is 0.5000 , and indicators $R_{13}$ and $R_{43}$ contribute the most to the risk coupling movement. These two risk factors continuously expand their risks in the process of coupling movement and combine with the contribution of index $R_{21}$ (unreasonable mechanical installation), which can trigger the coupling movement of human, machine, and management risks at any time. Finally, a four-factor risk coupling is formed due to the contribution of indicator $R_{31}$ (natural environment factor). At this time, the probability of risk coupling accidents caused by four factors is very high, which seriously threatens the safety defense system of subway engineering construction. The following paragraphs will introduce the most serious safety risk accidents during the construction of the Tianjin subway. Details are as follows.
During the construction of the Tianjin subway project, quicksand phenomenon is straightforward to occur in rainy season due to abundant groundwater and sufficient supplies in the construction section. The excavation length from the administrative center station to the right line of the Cultural Center Station is $155 \mathrm{~m}$. The shield machine cannot operate due to the blockage of the spiral machine by large rocks. When the observation hole is opened for treatment, sand and water gushed from the observation hole of the spiral machine. According to the investigation of the project department, the following reasons exist:

(1) Human factors: first of all, the construction personnel opened the observation hole cover and caused water gushing, which seriously violated the relevant regulations in the "Operation Manual of Shield Machine." Secondly, the construction personnel were not aware of risks and hidden dangers of special bottom operations and lack of construction experience. The two reasons mentioned above directly led to the accident. 
(2) Mechanical factors: appropriate shield machine cutters were not installed because of not taking into account the unique geological conditions in the area (disc cutter should be used for this geological condition). During the construction process, the shield machine was blocked by large rocks and deformation occurred at part of segments, which caused machine nonoperational.

(3) The geological conditions in the construction site are complex, which is located in the artesian aquifer. This condition has a great potential safety hazard, which is an important factor leading to water gushing and mud gushing accidents.

(4) Management factors: the mechanical management system and postsafety responsibility system have not been strictly implemented.

The aforementioned accidents are mainly caused by the failure to control the management risk factors and the operation errors of construction personnel and indirectly caused by mechanical and environmental risk factors. The cause of the formation is consistent with the result of fourfactor coupling calculated by the model, and the safety risk evaluation model has certain practicability. When evaluating the security risk system, the construction units put forward the subjective factors aiming at the risk factors and provided corresponding control measures, such as informing higher level timely and implementing corresponding control measures according to the relevant requirements of the emergency management system, which limited the safety accident from deterioration and expanding at the maximum level. During the construction of Tianjin subway project, many unexpected accidents happened, but safety engineers prevented coupling of safety risk factors in advance according to the action list and formulated corresponding decoupling measures to prevent the occurrence of major safety accidents and avoid economic losses caused by safety risk accidents.

4.3.2. Accident Prevention Measures. Based on the analysis of the above results, the safety engineer can monitor the development level of the safety system and the most risk factors by using the calculation results of the efficacy value and the coupling value. Aiming at different risk coupling levels, preventive measures are taken in advance from the aspects of human, machine, environment, and management.

When the coupling level of the security risk system is level $1, C \in[0,0.3)$, it is in low level of risk coupling. The risk coupling movement has few destructive influences on the safety defense system. At this time, the coupling movement among various risks should be prevented from damaging the safety defense system, and the most basic risk prevention measures should be taken. The specific measures are as follows:

(1) Human factors:

(a) Selecting the experienced constructor and preferably those with advanced technology and ensuring that all workers have relevant certificates (b) Compile the construction time of the labor team rationally to avoid fatigue construction

(c) Ensuring the logistic support of the constructor and keeping regular communication

(2) Mechanical factors:

(a) Setting up machinery and equipment usage accounting to monitor the usage status of machinery and equipment

(b) Formulating the shield machine installation management manual to ensure the shield machine installation reasonable

(3) Environmental factors:

(a) Ensuring the accuracy of geological exploration report and fully understanding the geological situation of the construction site

(b) Organizing the constructor to learn the safety and civilized construction standards promulgated by the state

(c) Recording every index of construction environment everyday to ensure a good working environment

(4) Management factors:

(a) Establish and perfect emergency management system, mechanical management system, safety management system, and organization management system

When the coupling level of the security risk system is level 2-level 3, $C \in[0.3,0.7]$, it is a risk coupling between middle and higher levels. At this time, the destructive power of the risk coupling movement is enhanced, and the confrontation and running-in of these risk factors are becoming increasingly fierce. Risk factors gradually break through the security defense system and trigger new risks. The coupling degree of the safety risk system of Tianjin subway project in this study is $C=0.6997$, which belongs to grade 3 . However, the phenomenon of coupling movement of subjective factors is more obvious. Special attention should be paid to the influence of subjective factors on system safety, and decoupling measures of human factors and management factors should be strengthened. More effective risk control measures should be drawn up aiming at the 4 risk factors, which are as follows:

(1) Human factors:

(a) Construction personnel should be evaluated by special management personnel quarterly to assess their ability. The personnel who fail to pass the evaluation shall be given special training, and those who fail to pass the training shall be eliminated.

(b) Record the working hours of construction personnel daily, which should not exceed 8 hours, to avoid fatigue construction.

(c) Psychological evaluation of the construction personnel should be done quarterly, and targeted 
communication and inspiration for the construction personnel with negative emotions should be conducted.

(2) Mechanical factors:

(a) The damaged machinery should be found and repaired in time from the mechanical equipment usage account and cannot be put into use again after testing

(b) The constructor shall be trained in the shield machine installation management manual monthly to strengthen their familiarity with the operation of the shield machine and avoid similar problems

(3) Environmental factors:

(a) Ensuring the accuracy of geological exploration report and fully understanding the geological situation of the construction site.

(b) Organizing and studying the geological survey report and making the special construction organization design in advance in view of possible risk problems in the geological survey report.

(c) Establishing an intelligent system for correlation of monitoring data. This measure can effectively reduce the degree of influence of environmental factors on human beings and reduce the coupling risk of subjective factors.

(4) Management factors:

(a) Strengthen construction site management and safety education. When risk coupling occurred, more attention should be paid by means of raising safety awareness and take active measures.

(b) The construction unit shall make emergency plans in advance of the project, and emergency drills should be conducted regularly.

When the coupling level of the security risk system is level 2-level 3, $C \in[0.7,1)$, it is in high level of risk coupling. At this time, the risk of the safety system is fully coupled, and the safety defense system has been completely destroyed. The coupling risk has actual impact on the construction safety. The construction safety system should adopt effective risk management strategies and methods to decouple the coupling risk. The specific measures are as follows:

(1) Integral arrangement for risk prevention should be made by the decision-makers, and working group should be set up quickly in case of emergency happens to provide quick response to the emergency situation

(2) Based on the construction safety situation, the corresponding emergency measures should be started immediately to avoid losses from expanding

(3) The possible chain risks can be foreseen by means of law of risk-coupling movement and the work experience of the constructor, and the risk bearing capacity of weak links should be strengthened timely

\section{Conclusion}

In this paper, system dynamics, cloud model, entropy weight method, and expected utility function are used to improve and enrich the coupling degree model, and the quantitative calculation model of coupling degree is established and applied to practical cases. Among them, the application of system dynamics provides a basic view for observing the risk coupling movement of the system, which enables engineers to have more intuitive observation of the risk coupling movement of the safety risk system. To some extent, the cloud model solves the subjectivity of expert evaluation data and provides a more reasonable method for data preprocessing. Therefore, the calculated value of the coupling degree model is more accurate and scientific than other models. According to the calculation results of actual cases, the coupling degree of the safety risk system in shield tunnel construction is 0.6997 . From it, engineers can assess and monitor risks according to the value of system coupling degree, which is in high level of coupling and in an unbalanced development stage and is extremely prone to safety risk accidents. Engineers can also know that the contribution of environmental risk factors is the greatest, and measures should be taken immediately to control the harm of environmental risk factors to the safety prevention system, so as to reduce the coupling degree of the safety risk system. This work can better reflect the coupling state of the safety risk system and contribute to theory and practice, given in detail in the following sections.

5.1. Improvement to the Theory. The causes of 101 subway tunnel construction safety risk accidents were analyzed, and the existing subway tunnel construction safety index system was supplemented in this study. The comprehensive indexes of the safety risk system and the criterion of system coupling degree for shield tunnel construction are established, and the weights and evaluation data of each index were obtained through questionnaires. This index system considers both practical and theoretical factors. The project provides a comprehensive index system and reasonable indicator evaluation criteria for studying the safety risk system of shield tunnel construction. This paper provides a reference for the establishment of the comprehensive index system of the construction safety risk system in other fields. In addition, by using system dynamics, cloud model, entropy weight method, and expected utility function to enrich the coupling model, the evaluation and monitoring ability of the model are finally enhanced.

5.2. Guidance on Practical Work. This work provides a new method for studying safety risk accidents of tunnel construction in the subway shield zone, which is to calculate the contribution value of risk factors to the occurrence of safety risk accidents and the coupling value of risk factors in the safety risk system. These values can be used to determine the development status of the safety risk system and the main risk factors affecting the development status of the safety risk system. This method can be used to indicate main risk 
factors of construction monitoring safety risk system in other fields which should be prevented and controlled and its development.

\section{Limitations and Future Scope}

Similar to other empirical studies, this study also has some limitations. In the data preprocessing, an extensive human labor is needed to repeat the step of cloud model for analysis, which is a time-consuming process. The actual cases selected in this study do not represent the tunnel construction conditions around the world. Therefore, the follow-up researchers should improve the method according to the actual situation in the region. Because the comprehensive index system of the safety risk system in this study is established through the collection of 101 safety risk accidents of the subway tunnels construction in China and the perfection of the index system in the existing research, it is not a global comprehensive index system. Therefore, the followup researchers can further improve the comprehensive index system by combining the safety risk accidents of subway tunnel construction in various countries and existing research. Follow-up researchers can also use relevant computer software to construct the risk dynamic coupling model so that readers can intuitively understand the process of risk coupling movement and the key control points of risk coupling movement. Thus, this study can be used as a reference study for the tunnel construction safety risk system. The proposed approach can be better generalized by applying in other domains, such as highway and railway tunnel engineering.

\section{Data Availability}

The data used to support the findings of this study are included within the article.

\section{Conflicts of Interest}

The authors declare that they have no conflicts of interest.

\section{References}

[1] Editorial Office of China Journal of Highway and Transport, "Review on China's tunnel engineering research.2015," China Journal of Highway and Transport, vol. 28, no. 5, pp. 1-65, 2015.

[2] Urban Rail Transit Association of China, "Data statistics: urban rail transport 2017 annual statistics and analysis report," 2018, http://www.camet.org.cn/index.php? $\mathrm{m}=$ content $\& \mathrm{c}=$ index $\& \mathrm{a}=$ show $\&$ catid $=18 \& \mathrm{id}=13532$.

[3] H. R. Lee, Q. M. Lee, and Y. Lu, "Statistical analysis on regularity of subway construction accidents from 2002 to 2016 in China," Urban Rapid Rail Transit, vol. 30, no. 1, pp. 12-19, 2007.

[4] Z. Yang, Research on Risk Management about Subway Shield Tunnel Construction of Line 2 of Zhengzhou, Lanzhou Jiaotong University, Lanzhou, China, 2015.

[5] Y. C. Zhen and H. Lee, "Application of ANP-FE and numerical simulation in the risk assessment and management of a subway tunnel during adjacent excavation," Modern Tunnelling Technology, vol. 50, no. 3, pp. 24-39, 2013.

[6] J. J. Reilly, "The management process for complex underground and tunneling projects," Tunnelling and Underground Space Technology, vol. 15, no. 1, pp. 31-44, 2000.

[7] X. G. Wu, B. J. Ding, L. M. Zhang, Y. Q. Chen, L. M. Xue, and R. X. Song, "Research on risk management of subway construction based on Bayesian network," China Safety Science Journal, vol. 24, no. 1, pp. 84-89, 2014.

[8] T. Isaksson, "Tunnelling in poor ground-choice of shield method based on reliability Eel," in Proceedings of European Conference on Soil Mechanics and Geotechnical Engineering, pp. 527-534, Porec, Croatia, May 1998.

[9] R. L. Sousa and H. H. Einstein, "Risk analysis during tunnel construction using Bayesian Networks: Porto Metro case study," Tunnelling and Underground Space Technology Incorporating Trenchless Technology Research, vol. 27, no. 1, pp. 86-100, 2011.

[10] C. Samantra, S. Datta, and S. S. Mahapatra, "Fuzzy based risk assessment module for metropolitan construction project: an empirical study," Engineering Applications of Artificial Intelligence, vol. 65, pp. 449-464, 2017.

[11] J. X. Liu, Research on Near-Miss Management Based on Hazards in Subway Construction Stage, Xi'an University of Science and Technology, Xi'an, China, 2018.

[12] X. C. Xiao, "Cause analysis of C824 bid section failure of Singapore metro loop line (I) - the general situation of the project and the process of the accident," Modern Tunnelling Technology, vol. 46, no. 6, pp. 66-72, 2009.

[13] T. Shang, Application Research on Risk Evaluation of Infrastructure Construction-Taking Fuzhou Metro Line 1 as a Case, Fuzhou University, Fuzhou, China, 2016.

[14] C. Yang, "Analysis of safety accidents in the construction period of Shenzhen metro phase II project," Railway Engineering, vol. 1, pp. 45-48, 2013.

[15] T. T. Zhang, "Identification of hazard sources in Metro accidents caused by improper design," Construction Safety, vol. 29, no. 9, pp. 53-59, 2014.

[16] Z. Ren, Study on the Coupling Models for Construction Risk of Deep Excavation in Subway Station, Huazhong University of Science \& Technology, Wuhan, China, 2013.

[17] L. L. Ma, Study on Operational Risk Coupling of Urban Rail Transit, Beijing Jiaotong University, Beijing, China, 2014.

[18] X. G. Wu, K. B. Wu, M. F. Shen et al., "Research on coupling of safety risks in metro construction based on N-K model," China Safety Science Journal, vol. 26, no. 4, pp. 96-101, 2016.

[19] H. Wang, Study on the Coupling Effect of Human-Environment Safety Risk Factors in Metro Construction, Xi'an Technological University, Xi'an, China, 2018.

[20] F. Luo and T. Q. Liu, "Coupled risk analysis of air traffic safety based on N-K model," Journal of Wuhan University of Technology, vol. 33, no. 2, pp. 267-279, 2011.

[21] Z. H. Luo, L. Zeng, and H. Z. Pan, "Research on construction safety risk assessment of new subway station close-attached undercrossing the existing operating station," Mathmatical Problems in Engineering, 2019.

[22] T. Xu, Study on Safety Risk Control of Shield Construction in Underwater Tunnel with Multiple Factor Coupling, Chongqing Jiaotong University, Chongqing, China, 2016.

[23] X. Y. Fu, X. X. Jin, and Q. Z. Shi, "Calculation and analysis of coupling degree of the transportation corridor \& economic belt system on the basis of ANN," Journal of the China Railway Society, vol. 32, no. 1, pp. 85-92, 2010. 
[24] Z. H. Luo, Y. F. Yang, and H. Z. Pan, "Research on performance evaluation system of shale gas PPP project based on matter element analysis," Mathmatical Problems in Engineering, vol. 2018, Article ID 4657383, 18 pages, 2018.

[25] M. Sugimoto, "Study on shield operation method in soft ground by shield simulation," Geotechnical Engineering, vol. 49, no. 2, pp. 182-191, 2018.

[26] L. Y. Ding, H. L. Yu, H. Li, C. Zhou, X. G. Wu, and M. H. Yu, "Safety risk identification system for metro construction on the basis of construction drawings," Automation in Construction, vol. 27, pp. 120-137, 2012.

[27] J. W. Zhang, Y. X. Chen, and T. Chen, "Analysis on the regularity and characteristics of tunnel construction accidents in China from 2006 to 2016," Modern Tunnelling Technology, vol. 55, no. 3, pp. 10-17, 2018.

[28] H. Liu, Z. C. Zhang, and L. J. Wang, "Statistical analysis of tunnel construction accidents in China from 2004 to 2008," Journal of Safety Sciences of China, vol. 20, no. 1, 2010.

[29] Q. F. Hu and J. B. Qin, "Statistical analysis of subway tunnel construction accidents in 2003-2011," Journal of Underground Space and Engineering, vol. 9, no. 3, 2013.

[30] F. W. Li, X. L. Du, and M. J. Zhang, "Statistical analysis of accidents in metro construction," Journal of Underground Space and Engineering, vol. 10, no. 2, pp. 474-479, 2014.

[31] Z. Cao, The Research on Safety Risk Assessment and Disaster Control Technology of Metro Shield Construction in Xi'an, Xi'an University of Science and Technology, Xi'an, China, 2013.

[32] N. N. Yang, Identification and evaluation of safety risk in construction process of metro shield tunnel, Dalian Jiaotong University, Dalian, China, 2017.

[33] T. Q. Liu and F. Luo, "Analysis on constitution and coupling of air traffic security risk," Journal of Wuhan University of Technology, vol. 34, no. 1, pp. 93-97, 2012.

[34] Z. C. Qiao, Y. C. Sun, and J. Z. Zhao, "Research on key factors of construction quality in construction projects," Coal Engineering, vol. 47, no. 8, pp. 144-147, 2015.

[35] J. L. Xiao and R. A. Jia, "The method and application of causality diagram system archetype calculation," Journal of Nanchang University (Natural Science), vol. 34, no. 2, pp. 131-136, 2010.

[36] F. Wang, L. Ding, P. E. D. Love, and D. J. Edwards, "Modeling tunnel construction risk dynamics: addressing the production versus protection problem," Safety Science, vol. 87, pp. 101115, 2016.

[37] M. G. Yang, P. E. D. Love, H. Brown et al., "Organizational accidents: a systemic model of production versus protection," Journal of Management Studies, vol. 49, no. 1, pp. 52-76, 2012.

[38] G. W. Zhang, R. He, D. Y. Liu et al., "Evolutionary algorithms based on cloud model," Journal of Computer Science, vol. 31, no. 7, pp. 1082-1091, 2008.

[39] Z. H. Luo, J. He, and H. Z. Pan, "Research on the selection strategy of green building parts supplier based on the catastrophe theory and kent index method," Advances in Materials Science and Engineering, vol. 2016, Article ID 4673526, 12 pages, 2016.

[40] D. L. Xu, "Drawing cloud models by using Matlab," Sci-Tech Innovation and Productivity, vol. 1, pp. 108-110, 2016.

[41] M. J. Chen, H. Z. Pan, J. He, and W. Wei Miao, "The application of fuzzy entropy in subway tunnel water leakage," Chinese Journal of Underground Space and Engineering, vol. 12, no. S1, pp. 62-65, 2016.

[42] D. W. Liu, L. Yu, and B. Li, "Fuzzy-entropy theory comprehensive evaluation method and its application in building construction safety," Procedia Engineering, vol. 43, pp. 137142, 2012. 


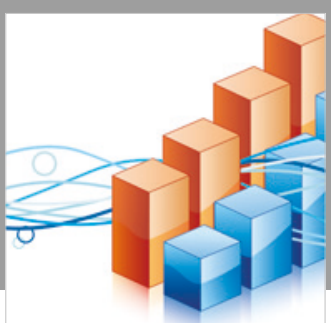

Advances in

Operations Research

\section{-n-m}
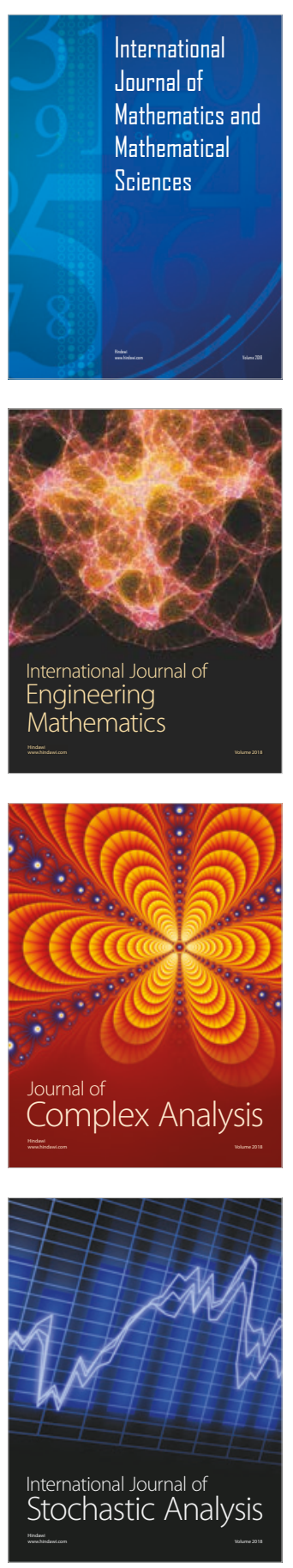
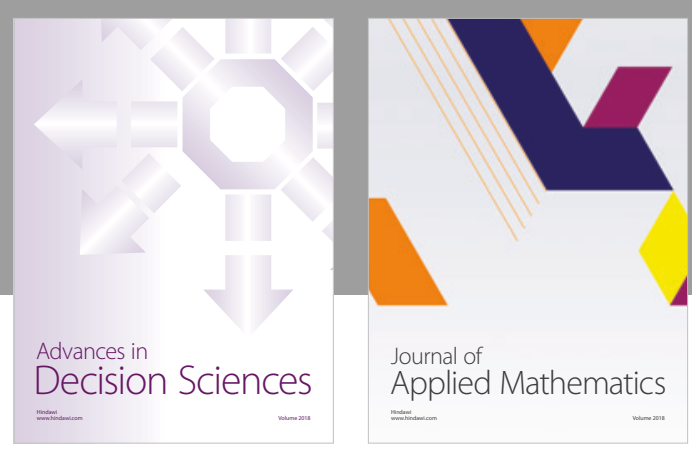

Journal of

Applied Mathematics
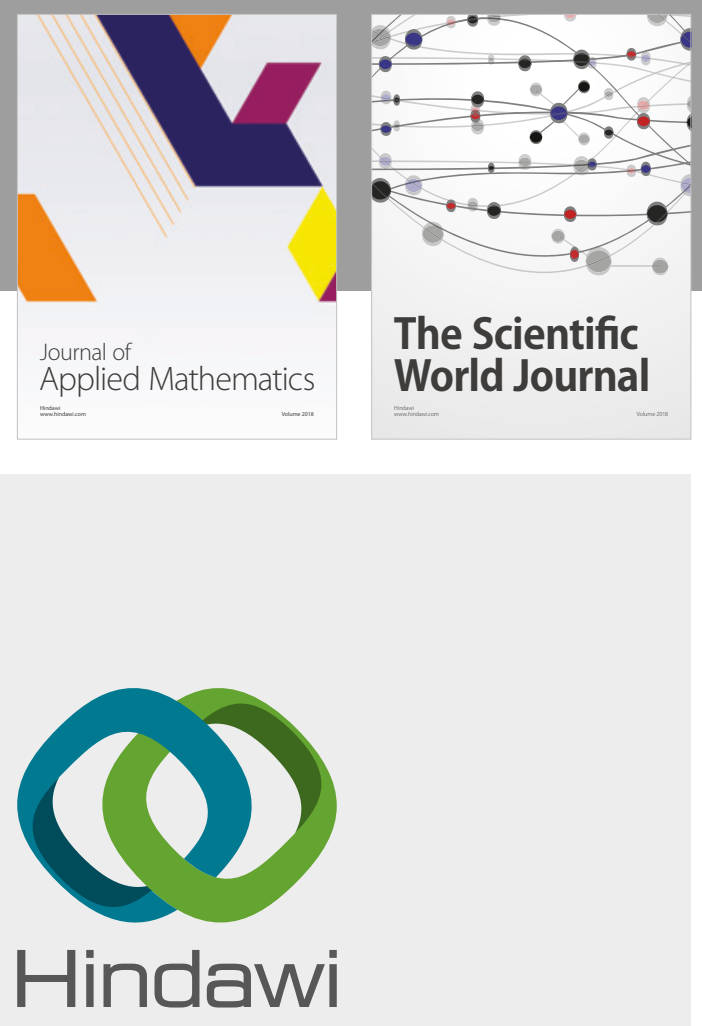

Submit your manuscripts at

www.hindawi.com

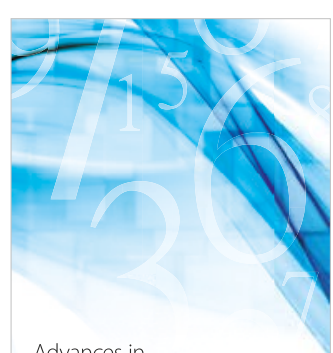

Advances in
Numerical Analysis
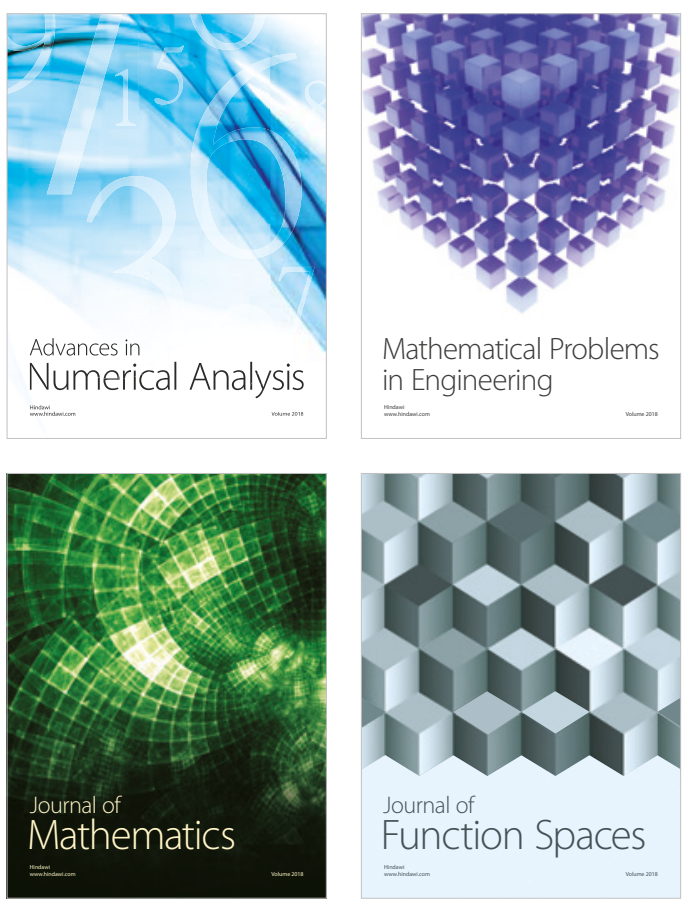

Mathematical Problems in Engineering

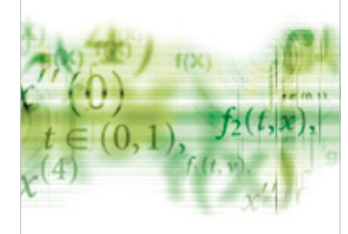

International Journal of

Differential Equations

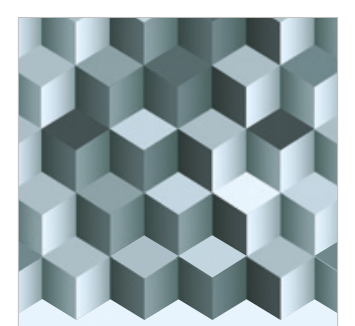

Journal of

Function Spaces

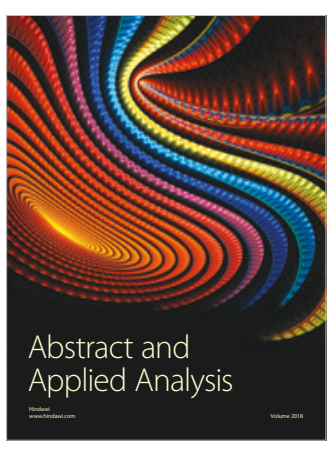

The Scientific

World Journal

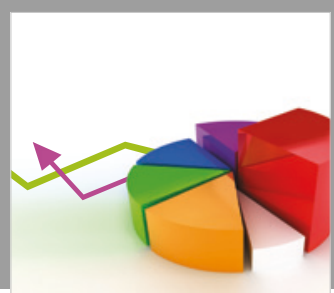

Journal of

Probability and Statistics
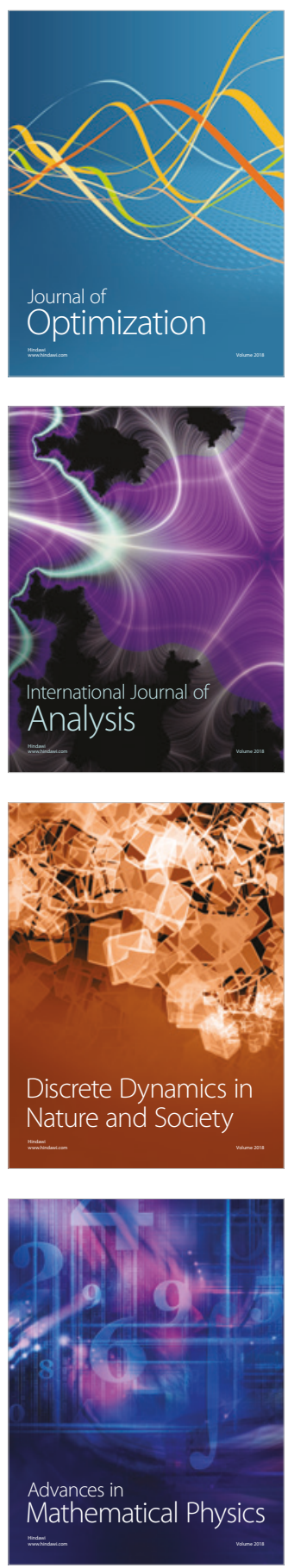